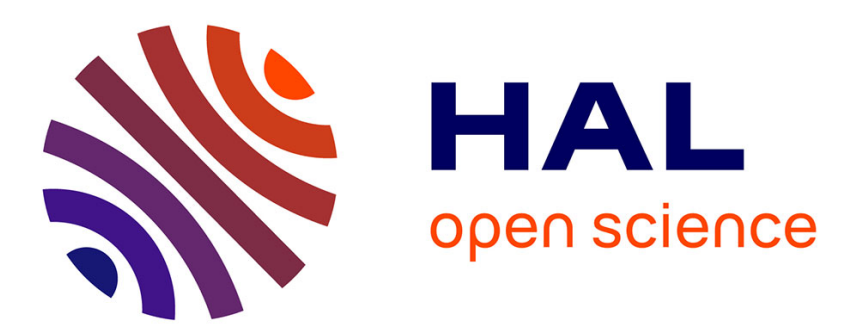

\title{
Insights into OCP Identification and Quantification in the Context of Apatite Biomineralization
}

Marc Robin, Stanislaw von Euw, Guillaume Renaudin, Sandrine Gomes, Jean-Marc Krafft, Nadine Nassif, Thierry Azaïs, Guylene Costentin

\section{To cite this version:}

Marc Robin, Stanislaw von Euw, Guillaume Renaudin, Sandrine Gomes, Jean-Marc Krafft, et al.. Insights into OCP Identification and Quantification in the Context of Apatite Biomineralization. CrystEngComm, 2020, 22 (16), pp.2728-2742. 10.1039/C9CE01972C . hal-02503877

\section{HAL Id: hal-02503877 https: / hal.sorbonne-universite.fr/hal-02503877}

Submitted on 10 Mar 2020

HAL is a multi-disciplinary open access archive for the deposit and dissemination of scientific research documents, whether they are published or not. The documents may come from teaching and research institutions in France or abroad, or from public or private research centers.
L'archive ouverte pluridisciplinaire HAL, est destinée au dépôt et à la diffusion de documents scientifiques de niveau recherche, publiés ou non, émanant des établissements d'enseignement et de recherche français ou étrangers, des laboratoires publics ou privés. 


\section{Insights for OCP Identification and Quantification in}

\section{the Context of Apatite Biomineralization}

Marc Robin a,b, Stanislas Von Euw a , Guillaume Renaudinc, Sandrine Gomes ${ }^{c}$, Jean-Marc Krafft ${ }^{b}$, Nadine Nassif ${ }^{a}$, Thierry Azaïs ${ }^{a^{*}}$ and Guylène Costentin ${ }^{b *}$

a Sorbonne Université, CNRS, Collège de France, Laboratoire Chimie de la Matière Condensée de Paris, LCMCP, F-75005 Paris, France

${ }^{b}$ Sorbonne Université, CNRS, Laboratoire Réactivité de Surface, LRS, F-75005 Paris, France

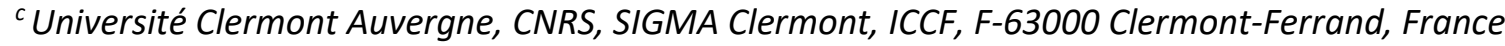

Corresponding authors: thierry.azais@upmc.fr; guylene.costentin@upmc.fr 


\section{Abstract}

Calcium phosphates (CaPs) are one of the major mineral families of wide interest in biomineralization and biomaterials development. The identification and quantification of the different CaPs phases (crystalline and amorphous) remains a major challenge in both in vitro and in vivo systems. This work aims to provide critical analysis of the different analytical techniques, Raman spectroscopy, solid-state NMR spectroscopy (ssNMR) and X-ray diffraction (XRD) that are used for the discrimination of octacalcium phosphate (OCP) from hydroxyapatite (HAp). Low amount of OCP ( 10 wt\%) can be detected by Raman spectroscopy in presence of biomimetic carbonated apatite (cHAp), providing that the $v\left(\mathrm{HPO}_{4}\right)$ contribution of weak intensity from $\mathrm{OCP}$ at $1008 \mathrm{~cm}^{-1}$ is observable or that spectral decomposition of the overlapped $v_{1}\left(\mathrm{PO}_{4}\right)$ bands from OCP and cHAp is performed. However, Raman is not suitable for quantification purpose. At reverse, the quantification of OCP in proportions down to $10 \mathrm{wt} \%$ is easily performed with ${ }^{31} \mathrm{P}$ solid state NMR. Opposite to solid state NMR, Raman can be implemented under in situ conditions to follow the time dependence of the biomineralization process without any sampling perturbation. An approach combining the advantage of in situ micro-Raman spectroscopy and the sensitivity of ex situ solid state NMR was used to monitor the formation of biomimetic carbonated apatite from an acidic aqueous solution of phosphate, carbonate and calcium ions. In relationship with the progressive increase of $\mathrm{pH}$, we identify the transient phases, precursors of cHAp: it is shown that an amorphous calcium phosphate phase (ACP) is first formed and subsequently transformed into OCP that then progressively turns into cHAp. Finally, powder X-ray diffraction coupled to Rietveld refinement was found very powerful to quantify very few amount of residual OCP in $\mathrm{CHAp}$ (down to $2 \mathrm{wt} \%$ ). Upon the OCP transformation into $\mathrm{CHAp}$, the decrease of the relative intensity of the (100) diffraction peak of the transient OCP phase was ascribed to an alteration of its hydrated layers, related to an incorporation of water molecules and/or carbonate anions upon reaction time. Such carbonate uptake in the course of transformation of OCP into cHAp could explain the origin of carbonate substitutions in the final biomimetic carbonated apatite. 
Keywords: in situ Raman, solid state NMR, OCP, carbonated apatite, precursors, Rietveld refinement 


\section{Introduction}

The unambiguous identification and quantification of CaP phases (crystalline or amorphous) formed in biomaterials development and in biomineralization context is of wide interest but remains challenging in both in vitro and in vivo system. ${ }^{1}$ Biomimetic carbonated hydroxyapatites (cHAp) are considered as model of bone mineral because of their structural similarities as cHAp are carbonated, Ca-deficient and poorly crystalline. ${ }^{2-4}$ Biomimetic cHAp particles also exhibit a nanometric size, a platelet shape and a core/layer organization where a hydrated amorphous calcium phosphate-like layer coats an apatite crystalline core. ${ }^{5}$ Several mechanisms have been proposed for the formation of biological apatite in particular through the investigation of in vitro systems. ${ }^{6-9}$ It is proposed that synthetic cHAp and biological apatite results from the transformation of metastable CaP phases considered as precursor phases. Specifically, octacalcium phosphate (OCP) is found to precede apatite formation in vitro ${ }^{6,10-13}$ and is proposed as a transient biological apatite precursor in vivo. ${ }^{14-16}$ Similar considerations are made for amorphous calcium phosphate (ACP) both in vitro ${ }^{9,17-20}$ and in vivo..$^{21-23}$

Infrared $(\mathrm{IR})^{24-28}$ and Raman ${ }^{12,} 27-35$ spectroscopies, electronic microscopies ${ }^{36,37}$ and X-ray diffraction (XRD) ${ }^{38-40}$ are widely used to characterize the nature of mineralized phases in biological tissues, cell cultures and biomaterials. Nevertheless, the close crystallographic structures of OCP and cHAp phases ${ }^{39}$ makes the unambiguous distinction of OCP from cHAp difficult when using these techniques. As an example, the superposition of OCP and cHAp X-ray diffraction patterns at wide angles, combined with nanometric size of the mineralized phases, is problematic. In a similar way, the overlap of the main $v_{1} \mathrm{PO}_{4}$ phosphate Raman bands of the various CaP phases makes difficult the unambiguous identification of the different CaP phases although Raman spectroscopy is widely used in the biomineralization field ${ }^{14,16,41,42}$ as it allows the study of hydrated and living materials. Thus, questions remain on the possibility to discriminate the distinct CaP phases in vivo. In contrast, solid state NMR (sSNMR) has been shown to be an efficient tool to identify the various CaP phases including $\mathrm{ACP}, \mathrm{OCP}$ and synthetic and biogenic $\mathrm{HAp} \mathrm{p}^{5,13,43-49}$ due to distinct ${ }^{31} \mathrm{P}$ resonances. Moreover, ssNMR can 
potentially provide quantitative data, but there is no reported data yet on its detection limit for the quantification of CaP phases.

Besides the difficulty in identifying and quantifying the presence of different CaP phases, another challenge is to monitor the precipitation of the $\mathrm{CaP}$ phases over time without any perturbations. Thus, it is of main interest to find suitable analytic tools to unambiguously distinguish and quantify cHAp from their precursor CaP phases, in particular amorphous calcium phosphate (ACP) and OCP, in both synthetic and biological-relevant media.

In this work, we provide a suitable and relevant approach for the identification and quantification of $\mathrm{cHAp}$ precursors ( $\mathrm{ACP}$ and $\mathrm{OCP}$ ) and the monitoring of their transformation into $\mathrm{CHAp}$ in a bioinspired context. ${ }^{50}$ First, physical powder mixtures of various proportions of OCP and CHAp were used as references to compare the ability of Raman and ${ }^{31} \mathrm{P}$ ssNMR to detect and quantify the presence of OCP vs. cHAp. Then, the advantages of the two spectroscopies (i.e. (i) real-time tracking and absence of perturbation of the reaction for in situ Raman, and (ii) easier discrimination and quantification of the CaP phases for ex situ NMR) were beneficially combined to monitor the precipitation processes of biomimetic cHAp. The progressive $\mathrm{pH}$ increase of an acidic calcium, phosphate and carbonate solution resulted in the precipitation of CaP phases that could be identified and quantified. Finally, Rietveld refinement analysis on X-ray powder diffraction (XRPD) data allowed to push up the detection limit of residual OCP present in $\mathrm{CHAp}$ and to discuss subtle structural modifications of OCP during its transformation into cHAp. 


\section{Experimental section}

Synthesis of biomimetic carbonated apatite (cHAp) and octacalcium phosphate (OCP)

The cHAp synthesis was performed according to the procedure described by Nassif et al. (referred as HA-2). ${ }^{50}$ Experiments were carried out at $22 \pm 1{ }^{\circ} \mathrm{C}$. Briefly, a solution of $110 \mathrm{mM} \mathrm{CaCl}, 33$ $\mathrm{mM} \mathrm{NaH} 2 \mathrm{PO}_{4}$ and $33 \mathrm{mM} \mathrm{NaHCO}$ was prepared in distilled water in order to preferentially synthesize B-type biomimetic carbonated apatite (cHAp) (where carbonates are substituting phosphate groups). ${ }^{4}$ The $\mathrm{pH}$ was adjusted to 2.2 with $12 \mathrm{M} \mathrm{HCl}$. Two flasks $(35 \mathrm{~mL}$, height $=50 \mathrm{~mm}$ ) containing these solutions $(20 \mathrm{~mL}$ ) and covered by perforated Parafilm (to slow down the gas diffusion) were placed into a closed chamber $\left(1000 \mathrm{~cm}^{3}\right)$. The precipitation was triggered via the slow increase of the $\mathrm{pH}$ of the solution induced by the diffusion of vapors of fresh ammonia aqueous solution ( $30 \% \mathrm{wt} / 8 \mathrm{~mL}$ ) in the chamber. In the present work, few drops of a universal indicator solution pH (Fluka-31282) were added to visually follow the evolution of $\mathrm{pH}$ gradient upon reaction time. A few minutes after ammonia introduction, precipitation occurs in the solution. After 6 days, the $\mathrm{pH}$ is 10 and the solid was washed and centrifuged $(6000 \mathrm{rpm}, 10 \mathrm{~min}$ ) first in distilled water and then in ethanol to remove the nonprecipitated salts. The recovered powder was dried at $37^{\circ} \mathrm{C}$ for 48 hours before characterization. This sample is hereafter referred to as cHAp.

In order to prepare CHAp with very low amount of residual OCP, several experiments were reproduced using similar protocol, but the syntheses were stopped before completion of the reaction and then sampled as described above after 1, 2 and 3 days. Samples are hereafter referred to as cHAp1d, cHAp-2d and cHAp-3d, respectively.

The synthesis of pure OCP was performed according to the procedure described by Bigi et al.

${ }^{51}$ It consists of the dropwise addition (1 drop per second) of $500 \mathrm{~mL}$ of $\mathrm{Ca}\left(\mathrm{CH}_{3} \mathrm{COO}\right)_{2} 0.04 \mathrm{M}$ into 1500 $\mathrm{mL}$ of a phosphate solution containing $10 \mathrm{mmol}$ of $\mathrm{Na}_{2} \mathrm{HPO}_{4}$ and $10 \mathrm{mmol}$ of $\mathrm{NaH}_{2} \mathrm{PO}_{4}$, with a starting $\mathrm{pH}$ of 5 . The reaction was performed at $70^{\circ} \mathrm{C}$ without stirring. The precipitate was then left in contact with the mother solution for $15 \mathrm{~min}$, filtered, washed with doubled distilled water, and dried at $37^{\circ} \mathrm{C}$. 
Various proportions of $\mathrm{CHAp}$ and OCP powders were intimately grounded in an agate mortar. The resulted physical mixtures were immediately characterized.

Ex situ Micro-Raman, in situ Raman spectroscopies and spectral decomposition

Ex situ micro-Raman analysis was performed on cHAp, OCP and physical mixtures of OCP/cHAp powders. Spectra of these samples were collected from a KAISER Optical system equipped with a charge coupled detector (CCD) and a LASER with $\lambda=785 \mathrm{~nm}\left(P_{\text {sample }} \sim 1 \mathrm{~mW}\right.$, resolution $=4 \mathrm{~cm}^{-1}$ accumulation time $=20 \mathrm{~s}, 5$ scans per spectrum) coupled with a microscope with a $50 \mathrm{x}$ lens.

In situ Raman spectroscopy was used to monitor the evolution of CaP precipitation during the cHAp synthesis previously described. Spectra of the samples were collected using the same KAISER Optical system $\left(P=10-12 \mathrm{~mW}\right.$, resolution $=4 \mathrm{~cm}^{-1}$ accumulation time $=150 \mathrm{~s}, 6$ scans per spectrum, 1 spectrum every 16 minutes) using a fiber optic Raman probe equipped with a sapphire optical lens. The probe was directly immersed in the ionic solution as show in Figure S1 prior to ammonia exposure and was left immobile during the CaP precipitation to prevent any deviation from the initial procedure. Time zero corresponds to the moment ammonia was introduced in a closed chamber.

\section{Solid-State Nuclear Magnetic Resonance}

Solid state nuclear magnetic resonance (ssNMR) experiments were performed on an AVANCE 500 Bruker spectrometer $\left(\mathrm{B}_{0}=11.7 \mathrm{~T}\right)$ operating at $\mathrm{v}\left({ }^{1} \mathrm{H}\right)=500.13 \mathrm{MHz}$ and $\mathrm{v}\left({ }^{31} \mathrm{P}\right)=202.40 \mathrm{MHz}$. The powder samples (OCP/cHAp physical mixture) were packed into $4 \mathrm{~mm}$ zirconia rotors and spun at a magic-angle-spinning frequency of $v_{\text {MAS }}=14 \mathrm{kHz}$. The ${ }^{31} \mathrm{P}$ NMR spectra were recorded through a single pulse experiment $(\pi / 6=1.3 \mu \mathrm{s})$ of 32 added scans acquired with proton-decoupling (SPINAL-64; $\mathrm{V}_{\mathrm{RF}}\left({ }^{1} \mathrm{H}\right.$ ) $=70 \mathrm{kHz}$ ). A recycle delay $\mathrm{RD}$ of $200 \mathrm{~s}$ was used in order to obtain quantitative ${ }^{31} \mathrm{P}$ spectra.

For the ex situ monitoring, wet samples were carefully extracted from the cHAp precipitation medium with a syringe and a $25 \mathrm{G}$ needle thus limiting the convection movements in the reaction flask. These wet samples were briefly centrifuged (10000 r.p.m.; 1 minute), placed into $4 \mathrm{~mm}$ zirconia rotor 
in-between two Teflon spacers and their ${ }^{31} \mathrm{P}$ ssNMR spectra immediately recorded. ${ }^{31} \mathrm{P}$ single pulse NMR experiments were performed in similar conditions (except $v_{\text {MAS }}=8 \mathrm{kHz}$ and 32-200 scans depending on the signal-to-noise ratio). In addition, ${ }^{1} \mathrm{H}-{ }^{31} \mathrm{P}$ cross-polarization (CP MAS) experiments were performed on cHAp still containing some OCP as a contaminant phase (cHAp-1d, cHAp-2d, cHAp3d) using a contact time $t_{\mathrm{CP}}$ of $1 \mathrm{~ms}$ (typically $v_{\mathrm{RF}}\left({ }^{1} \mathrm{H}\right)=55 \mathrm{kHz}$ and $\left.\nu_{\mathrm{RF}}\left({ }^{31} \mathrm{P}\right)=45 \mathrm{kHz}, \mathrm{RD}=2 \mathrm{~s}\right) .2 \mathrm{D}^{1} \mathrm{H}^{3}{ }^{31} \mathrm{P}$ HetCor experiment was recorded at $v_{\text {MAS }}=8 \mathrm{kHz}$ with similar conditions and using $180 \mathrm{t}_{1}$ increments of 80 scans.

For all NMR experiments, ${ }^{1} \mathrm{H}$ and ${ }^{31} \mathrm{P}$ chemical shift was referenced $(\delta=0 \mathrm{ppm})$ to TMS and $85 \mathrm{wt} \%$ aqueous $\mathrm{H}_{3} \mathrm{PO}_{4}$, respectively.

\section{Decomposition of Raman and NMR spectra}

The decomposition of Raman and NMR spectra was performed using the Dmfit program. ${ }^{52}$ The spectra of the reference samples OCP and CHAp were fitted first. The resulted positions, linewidths and relative intensities of the reference bands or resonances were kept constant for the decomposition of the physical mixture spectra.

$X$-rays powder diffraction (XRPD)

XRPD patterns were recorded on a PANalytical X'Pert Pro diffractometer, with $\theta-\theta$ geometry, equipped with a solid X-Celerator detector and using $\mathrm{Cu} K \alpha$ radiation $\left(\lambda=1.54184 \AA\right.$ ) with a $14^{\circ}$ divergence and a $5.5 \mathrm{~mm}$ anti-scatter slits. XRPD patterns were recorded at room temperature in the interval $3^{\circ}<2 \theta<120^{\circ}$, with a step size of $0.0167^{\circ}$ and a counting time of $200 \mathrm{~s}$ for each data value. A total counting time of about 200 min was used for each sample. A XRPD pattern was collected from pure NIST standard $\mathrm{LaB}_{6}$ using the same experimental conditions in order to extract the instrumental resolution function to improve peak profile fitting during Rietveld refinements using a pseudo-Voigt profile function.

Rietveld refinement 
Rietveld refinements were performed with the program Fullprof. $2 \mathrm{k}^{53}$ to determine the relative proportions of OCP and hydroxyapatite in $\mathrm{cHAp}-1 \mathrm{~d}, \mathrm{cHAp}-2 \mathrm{~d}$ and $\mathrm{cHAp}-3 \mathrm{~d}$. The structural parameters of hydroxyapatite, $\mathrm{Ca}_{5}\left(\mathrm{PO}_{4}\right)_{3} \cdot \mathrm{OH}$, were taken from ref. ${ }^{54}$ : space group $P 6_{3} / m, \mathrm{Z}=2, a=9.4218 \AA$ and $c$ $=6.8813 \AA$, 7 independent non- $\mathrm{H}$ atomic positions: two $\mathrm{Ca}$, one $\mathrm{P}$ and four $\mathrm{O}$ positions. The $\mathrm{O} 4$ oxygen position (i.e. the hydroxyl anion) is half occupied; this corresponds to a statistically disordered $4 e$ position around the $2 a\left(0,0, \frac{1 / 4}{4}\right)$ site. The structural parameters of $\mathrm{OCP}, \mathrm{Ca}_{8}\left(\mathrm{HPO}_{4}\right)_{2}\left(\mathrm{PO}_{4}\right)_{4}\left(\mathrm{H}_{2} \mathrm{O}\right)_{5}$, were taken from ref. ${ }^{40}$ : space group $P \overline{1}, \mathrm{Z}=2, a=19.692 \AA, b=9.523 \AA, c=6.835 \AA, \alpha=90.15^{\circ}, \beta=92.54^{\circ}$ and $\gamma=108.65^{\circ}, 44$ independent non- $\mathrm{H}$ atomic positions: eight $\mathrm{Ca}$, six $\mathrm{P}$ positions and thirty $\mathrm{O}$ positions (from which five positions correspond to water molecules). In order to lighten, and thus make stronger and more stable, the modeling process of the experimental diffraction data, the apatite phase was considered as non-substituted hydroxyapatite; and not a carbonated Ca-deficient hydroxyapatite which requires introducing additional parameters to be - not easily - refined. This simplification of the model is justified by the preservation of the hexagonal $P 6_{3} / m$ symmetry in the case of a B-type cHAp. ${ }^{55,}$ ${ }^{56}$ In a first step, the structural parameters were fixed to literature values. Then during the successive refinement cycles, all hydroxyapatite parameters were refined: first lattice parameters and peak profiles, next atomic parameters (positional, isotropic temperature and occupancy factors), and finally anisotropic peaks broadening. Due to the nanometric feature of the coherent domain size, the low symmetry of the OCP structure and the numerous independent crystallographic sites, structure parameters of OCP were kept fixed to literature values. Peak broadening, peak asymmetry and preferential orientation were systematically refined. To improve powder pattern refinements of cHAp$1 d, c H A p-2 d$ and $\mathrm{cHAp}-3 \mathrm{~d}$ samples, and in particular to account for the unusual weak intensity of the (100) reflection compared to $(1 \overline{1} 0)$ and (010); respectively at $2 \theta=4.55^{\circ}, 9.55^{\circ}$ and $9.73^{\circ}$, Rietveld simulations were finalized by varying the electronic density within the OCP hydrated layer. Expressing the electronic density as $n$ equivalent of water molecules, underhydrated and overhydrated OCP-based phases were investigated by formally removing or adding water molecules from the OCP nominal composition $\mathrm{Ca}_{8}\left(\mathrm{HPO}_{4}\right)_{2}\left(\mathrm{PO}_{4}\right)_{4} .\left(\mathrm{H}_{2} \mathrm{O}\right)_{5}$. Thanks to such modulation of the electronic density on the 
related water crystallographic sites ( $\mathrm{O} 25$ to $\mathrm{O} 30$ oxygen crystallographic sites from ref ${ }^{40}$ ), simulations were performed on the following compositions: $\mathrm{Ca}_{8}\left(\mathrm{HPO}_{4}\right)_{2}\left(\mathrm{PO}_{4}\right)_{4}$ (anhydrous composition obtained by removing the electronic weight on the six water crystallographic sites), $\mathrm{Ca}_{8}\left(\mathrm{HPO}_{4}\right)_{2}\left(\mathrm{PO}_{4}\right)_{4} \cdot\left(\mathrm{H}_{2} \mathrm{O}\right)_{4}$ (by removing the electronic weight onto the water crystallographic site along the hexagonal channel), $\mathrm{Ca}_{8}\left(\mathrm{HPO}_{4}\right)_{2}\left(\mathrm{PO}_{4}\right)_{4}\left(\mathrm{H}_{2} \mathrm{O}\right)_{6}$ (by formally doubling the electronic weight of the water crystallographic sites into the hexagonal channel) and $\mathrm{Ca}_{8}\left(\mathrm{HPO}_{4}\right)_{2}\left(\mathrm{PO}_{4}\right)_{4} \cdot\left(\mathrm{H}_{2} \mathrm{O}\right)_{10}$ (by doubling the electronic weight of the whole water crystallographic sites).

\section{Results and discussion}

\section{Detection limits in physical mixtures of OCP and cHAp}

\subsection{Limitation in the OCP vs. cHAp discrimination using Raman spectroscopy}

To evaluate the ability of Raman spectroscopy to address the detection of OCP in the presence of biomimetic apatite, Raman spectra of OCP/CHAp physical mixtures in various proportions were recorded. The recorded spectra of pure OCP $\left(\mathrm{Ca}_{8}\left(\mathrm{PO}_{4}\right)_{4}\left(\mathrm{HPO}_{4}\right)_{2} .5 \mathrm{H}_{2} \mathrm{O}\right)$ and cHAp phases (Fig. 1) are in agreement with the typical Raman spectra reported in the literature (Table 1). ${ }^{10,27,32}$ Concerning OCP, the $v_{1} \mathrm{PO}_{4}$ double band at 955 and $964 \mathrm{~cm}^{-1}$ is characteristic of the OCP phase (see the spectral decomposition in Fig. 1 green inset). ${ }^{12,29-31}$ The other vibration modes ascribed to $\left(\mathrm{PO}_{4}\right)$ and $\left(\mathrm{HPO}_{4}\right)$ moities are observed as broad massives of weak intensity. ${ }^{27}$ The requirement for numerous contributions for their decomposition is probably significant of the geometrical distortion of the related $\mathrm{PO}_{4}$ tetrahedra. Note the absence of any carbonate contribution around $1070 \mathrm{~cm}^{-1}$ in the pure OCP sample. 

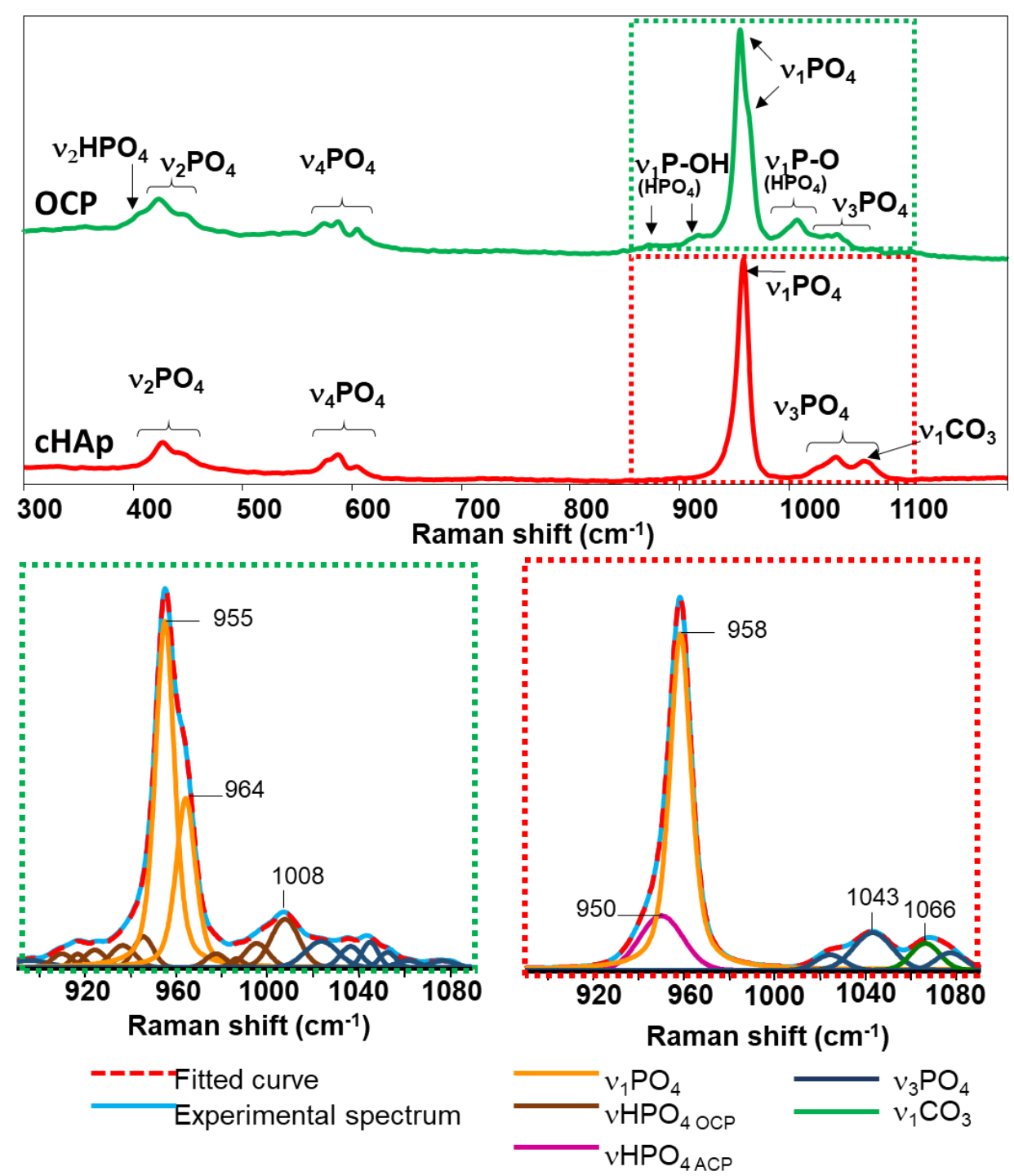

Figure 1. Raman spectra of octacalcium phosphate (OCP, green) and biomimetic apatite (cHAp, red). The green and red insets display the spectral decomposition (in the $890-1010 \mathrm{~cm}^{-1}$ region) of OCP and cHAp Raman spectra, respectively. 
Table 1. Positions of the Raman contributions obtained from Fig. 1 for OCP and CHAp and assignment based on literature data.

\begin{tabular}{|c|c|c|c|}
\hline \multicolumn{2}{|c|}{ OCP } & \multicolumn{2}{|c|}{$\mathrm{cHAp}$} \\
\hline Raman shift $\left(\mathrm{cm}^{-1}\right)$ & Assignment $^{12,27,29-31}$ & Raman shift $\left(\mathrm{cm}^{-1}\right)$ & Assignment ${ }^{12,28-35,57}$ \\
\hline \multirow[t]{2}{*}{$407(w)$} & $v_{2} \mathrm{HPO}_{4}$ & - & - \\
\hline & O-P-O bending modes & & \\
\hline \multirow[t]{2}{*}{$429(\mathrm{~m}), 447(\mathrm{~m})$} & $\mathrm{V}_{2} \mathrm{PO}_{4}$ & $427(m), 444(w)$ & $\mathrm{v}_{2} \mathrm{PO}_{4}$ \\
\hline & $\mathrm{O}-\mathrm{P}-\mathrm{O}$ bending modes & & O-P-O bending modes \\
\hline \multirow{2}{*}{$\begin{array}{l}575(w), 587(w) \\
605(w)\end{array}$} & $V_{4} \mathrm{PO}_{4}$ & \multirow{2}{*}{$\begin{array}{l}578(m), 588(m) \\
605(w)\end{array}$} & $v_{4} \mathrm{PO}_{4}$ \\
\hline & $\begin{array}{l}\mathrm{P}-\mathrm{O} \text { and } \mathrm{O}-\mathrm{P}-\mathrm{O} \text { stretching } \\
\text { and bending modes }\end{array}$ & & O-P-O bending modes \\
\hline $917(v w), 924(v w)$ & $\mathrm{HPO}_{4}$ & \multirow[t]{2}{*}{$950(\mathrm{~m})^{*}$} & $\mathrm{HPO}_{4}$ \\
\hline $935(w), 945(w)$ & $\mathrm{P}-\mathrm{OH}$ stretching modes & & $\begin{array}{l}\mathrm{P}-\mathrm{OH} \text { stretching } \\
\text { modes }\end{array}$ \\
\hline \multirow[t]{2}{*}{955 (vs), 964 (sh) } & $v_{1} \mathrm{PO}_{4}$ & \multirow[t]{2}{*}{958 (vs) } & $v_{1} \mathrm{PO}_{4}$ \\
\hline & P-O stretching modes & & P-O stretching modes \\
\hline \multirow{2}{*}{$\begin{array}{l}1008(\mathrm{~m}), 995(\mathrm{w}) \\
977(\mathrm{vw})\end{array}$} & $\mathrm{v}_{1} \mathrm{HPO}_{4}$ & \multirow[t]{2}{*}{-} & - \\
\hline & P-O stretching modes & & \\
\hline \multirow{2}{*}{$\begin{array}{l}1024(w), 1036(w) \\
1044(w), 1052(v w)\end{array}$} & $\mathrm{V}_{3} \mathrm{PO}_{4}$ & \multirow{2}{*}{$\begin{array}{l}1024(\mathrm{w}), 1043(\mathrm{~m}), \\
1077(\mathrm{~m})\end{array}$} & $\mathrm{v}_{3} \mathrm{PO}_{4}$ \\
\hline & P-O stretching modes & & $\mathrm{P}-\mathrm{O}$ stretching modes \\
\hline \multirow[t]{2}{*}{$1113(v w)$} & $v_{3} \mathrm{HPO}_{4}$ & $1066(\mathrm{~m})$ & $\mathrm{v}_{1} \mathrm{CO}_{3}$ \\
\hline & P-O stretching modes & & stretching modes \\
\hline
\end{tabular}

$\mathrm{vw}=$ very weak; $\mathrm{mw}=$ medium weak; $\mathrm{m}=$ medium; s=strong; $\mathrm{sh}=$ shoulder;

*contribution assigned to $A C P^{10}$

On the other hand, the Raman spectrum of biomimetic cHAp exhibits an asymmetrical-shaped $V_{1} \mathrm{PO}_{4}$ band centered at $958 \mathrm{~cm}^{-129-35}$ that can be decomposed into a main component at $958 \mathrm{~cm}^{-1}$ and a broader one at $950 \mathrm{~cm}^{-1}$ characteristic of crystalline hydroxyapatite ${ }^{28}$ and ACP phase, ${ }^{10}$ respectively. As it has been recently evidenced that these biomimetic cHAp nanoparticles are composed of a crystalline apatitic core coated by an ACP-like layer, ${ }^{58}$ we assign the sharp band at $958 \mathrm{~cm}^{-1}$ to the crystalline apatitic core and the broad component at $950 \mathrm{~cm}^{-1}$ to the ACP-like surface layer. ${ }^{10,12}$ The 
$v_{3} \mathrm{PO}_{4}$ contributions, ranging from 1010 to $1090 \mathrm{~cm}^{-1}$ overlap with the $v_{1} \mathrm{CO}_{3}$ contribution of carbonates at $1066 \mathrm{~cm}^{-1}$ (Fig. 1, red inset, Table 1). ${ }^{57}$ This detected carbonate contribution (absent in the case of the OCP spectrum) is coherent the carbonation expected for $\mathrm{cHAp}\left(\sim 5 \mathrm{wt} \%\right.$ as reported previously $\left.{ }^{50}\right)$.

To estimate the sensitivity of the Raman spectroscopy to detect OCP in presence of cHAp, spectra OCP/cHAp physical mixtures with various relative proportions were recorded (Fig. 2a). Based on the visual tracking of the characteristic shoulder of OCP at $964 \mathrm{~cm}^{-1}$, the presence of OCP is only clearly detected for high OCP content ( $\geq 70 \mathrm{wt} \%$ ). For lower OCP content, a slight shift of the maximum of the $v_{1} \mathrm{PO}_{4}$ band is observed due the overlapping with those from cHAp. In contrast to stoichiometric crystalline hydroxyapatite, ${ }^{28}$ the low crystallinity of $\mathrm{cHAp}$ results in the broadening of the Raman bands $^{32,59}$ that even increases the overlap with those from OCP, making ambiguous the identification of the two phases. Hence, unless OCP is largely predominant ( $\geq 70 \mathrm{wt} \%$ ), OCP cannot be readily identified in the presence of biomimetic carbonated apatite through the visual observation of the $v_{1} \mathrm{PO}_{4}$ Raman bands. 


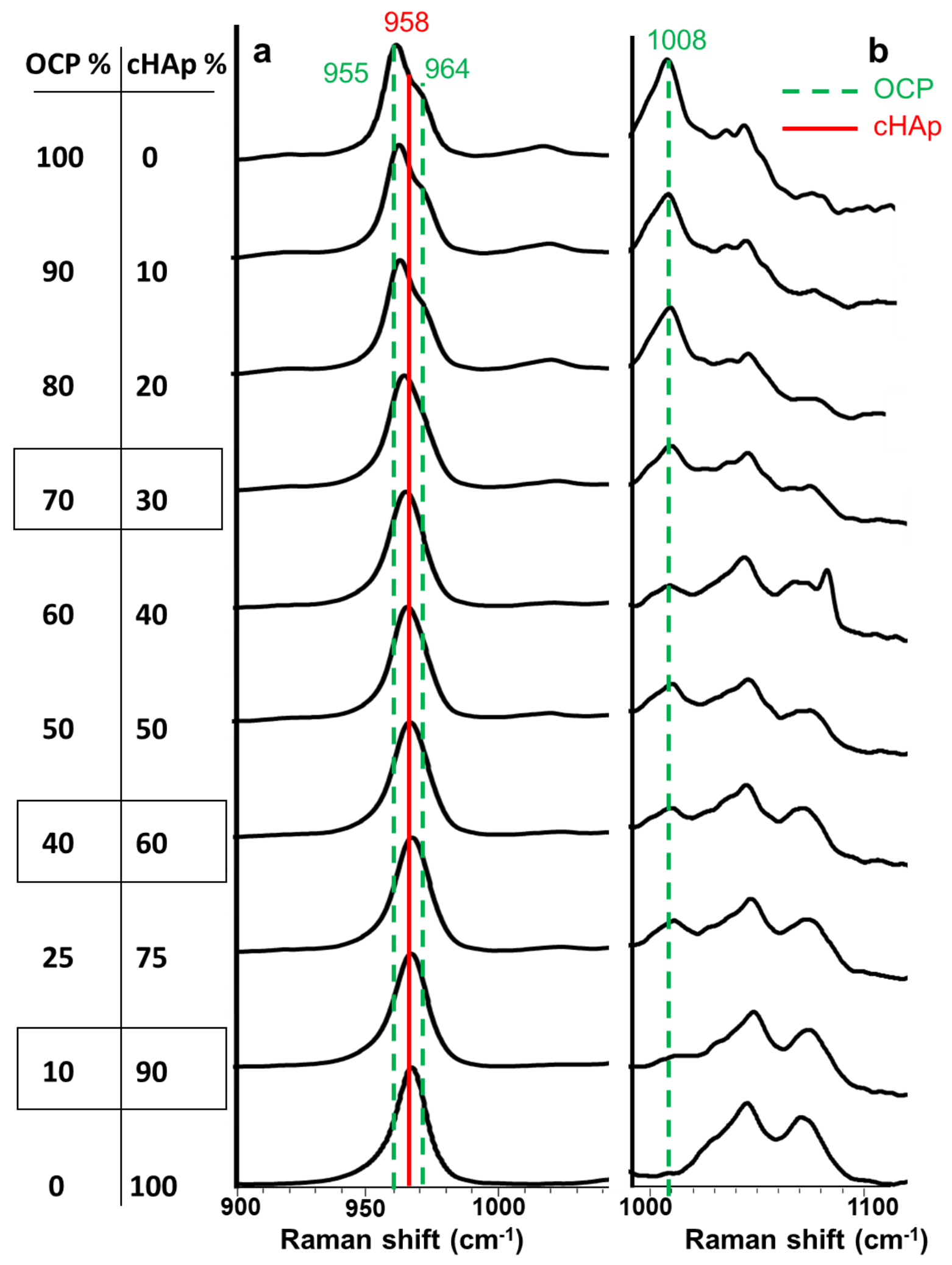

Figure 2. Raman spectra of various OCP/cHAp physical mixtures: (a) $v_{1} \mathrm{PO}_{4}$ region and (b) zoom of the region of the $\mathrm{HPO}_{4} / \mathrm{CO}_{3}{ }^{2-}$ contributions. Green doted lines and red solid line represent OCP and $\mathrm{cHAp}$ contributions, respectively. 
To allow overcoming such visual limitation (Fig.2a), other Raman bands such as those centered at $407 \mathrm{~cm}^{-1}$ and $1008 \mathrm{~cm}^{-1}$ characteristic of the OCP structure (respectively ascribed to ${ }_{2} \mathrm{HPO}_{4}$ and n1HPO4 vibrations modes) could be considered (Table 1). However, only that at $1008 \mathrm{~cm}^{-1}$ is well resolved from other contributions present in HAp (Fig.1). Despite its low relative intensity compared to the main $\mathrm{v}_{1} \mathrm{PO}_{4}$ bands (Fig.1), this contribution may be particularly useful to probe the presence of OCP due to the absence of signal in this region for cHAp. Hence, according to the zoom of this region (Fig.2b), OCP is clearly detected from 10 wt\% and its intensity increases with the OCP content. However, considering the low absolute intensity of this contribution, its detection requires peculiar attention to optimize the $\mathrm{S} / \mathrm{N}$ ratio. In addition, in the context of in situ Raman measurements implemented in biomineralization systems as cell cultures ${ }^{16,41}$ or tissue cultured ex vivo, ${ }^{14}$ other overlapping contributions originating from organic compounds make difficult the use of this spectral region to conclude on the presence of OCP.

To overcome this difficulty, an alternative to improve the detection limits of OCP in presence of $\mathrm{cHAp}$ consists in spectral decomposition of the $\mathrm{v}_{1} \mathrm{PO}_{4}$ region. The experimental spectra of OCP/cHAp physical mixtures were fitted starting from the positions, linewidths and relative intensity of the two $v_{1} \mathrm{PO}_{4}$ components extracted from the spectra related to pure substances OCP and cHAp (Fig. 1, Fig. S2a, b). As illustrated in (Fig. S2c and S2d), the introduction of the two sets of components corresponding to $\mathrm{OCP}$ and $\mathrm{CHAp}$ is required to fit the experimental spectra of the physical mixtures (OCP/cHAp: $10 / 90$ and 40/60, respectively): thus low OCP content (10 wt\%) can be qualitatively detected by Raman providing spectral decomposition is processed. However, despite quite good accuracy of the spectral decomposition of the physical mixtures spectra, the extracted areas of the fitted contributions of the two sets of components corresponding to OCP and CHAp do not lead to accurate semi quantification (Fig. S2c and S2d). This confirms that due to dependence of the signal to numerous parameters other than concentration such as surface/volume ratio, diffusion of the particles, Raman is not suitable for quantification purpose. 


\subsection{Identification and quantification of OCP from CHAp using ${ }^{31} P S s N M R$}

Unlike their Raman signals, the ${ }^{31} \mathrm{P}$ ssNMR resonances of OCP and CHAp exhibit distinct chemical shifts. The ${ }^{31} \mathrm{P}$ ssNMR spectrum of pure OCP exhibits typical resonances at 3.3 and $3.0 \mathrm{ppm}$ for the phosphates from the apatitic layers (sites P4 and P1, respectively, according to Davis et al. ${ }^{44}$ ) and at 1,7, -0.1 and -0.3 ppm from the hydrated layers (P2, P6 and merged P3 and P5, respectively, according to Davis et al. ${ }^{44}$ ) while pure $\mathrm{cHAp}$ is characterized by a resonance at $2.8 \mathrm{ppm}$.

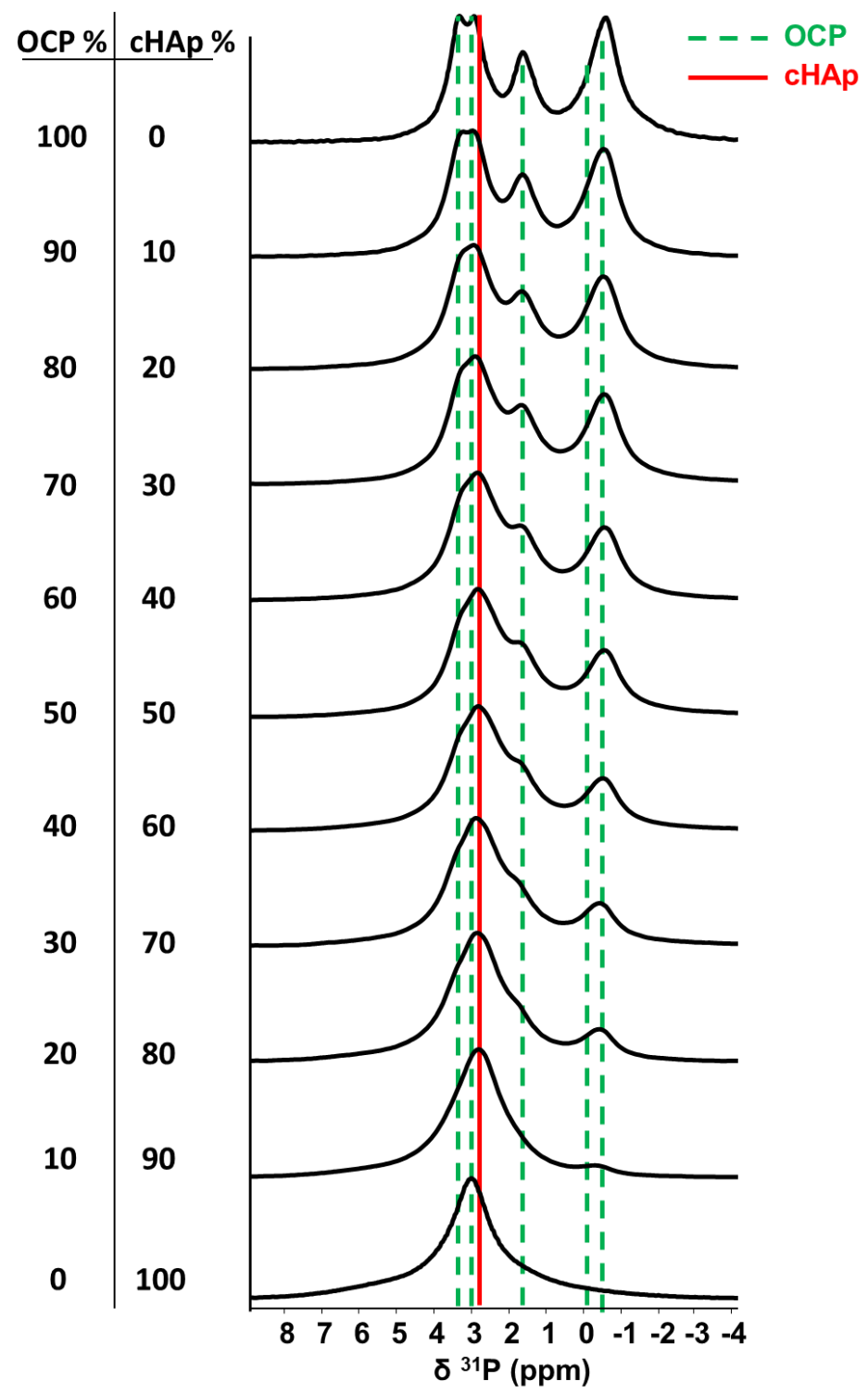

Figure 3. ${ }^{31} \mathrm{P}$ single pulse MAS spectra of various OCP/CHAp physical mixtures. Green doted lines and red solid line represent $O C P$ and $C H A p$ resonances, respectively. 
Contrary to Raman, small proportions of OCP in OCP/cHAp physical mixtures are readily detected through ${ }^{31} \mathrm{P}$ MAS NMR (Fig. 3) due to the ${ }^{31} \mathrm{P}$ resonances of OCP hydrated layers $(\sim 1.7$ and $0.3 \mathrm{ppm})$. As an example, the presence of $10 \mathrm{wt} \%$ of OCP is unambiguously detected with ${ }^{31} \mathrm{P}$ ssNMR without additional data processing.

In principle, NMR spectroscopy allows the extraction of quantitative data (i.e. the relative proportion $\mathrm{OCP} / \mathrm{CHAp}$ ) from the ${ }^{31} \mathrm{P}$ single pulse MAS NMR spectra. The Figure S3a displays the decomposition of the various spectra of the physical mixture OCP/cHAp. Spectra were fitted by keeping constant (i) position and linewidth of the ${ }^{31} \mathrm{P}$ resonances of $\mathrm{CHAp}$ and OCP extracted from the pure cHAp and OCP spectra, (ii) as well as the relative intensities of the several phosphorus resonance contributions of the OCP. Unlike in the case of Raman spectra, the good accuracy of the fits performed for mechanical mixtures whatever the mass ratio and even at low amount of OCP (10/90) (Fig. S3a) allows the establishment of a calibration curve (Fig. S3b) to extract quantitative data based on ${ }^{31} \mathrm{P}$ NMR.

\section{Monitoring the precipitation of biomimetic apatite over time}

\subsection{Combination of in situ Raman and ex situ ssNMR}

Monitoring the carbonated apatite formation over time remains a great challenge in bone biomineralization. This is mainly due to the process of bone remodelling that leads to the continuous deposition and dissolution ${ }^{60}$ of the mineral, but also by the fact that mineral undergoes extensive chemical post-modifications after their synthesis and initial deposition. ${ }^{61}$ Mineral crystallites with poorly crystalline structure are subject to maturation processes involving changes in their chemistry and coherent domain size. ${ }^{62}$ Thus, studying bioinspired protocols is of great interest to improve knowledge on apatite biomineralization. Here, we rely on a biomimetic synthesis of cHAp already published in the literature, ${ }^{50}$ where $\mathrm{cHAp}$ is obtained starting from an acidic aqueous solution of phosphates, carbonates and $\mathrm{Ca}^{2+}$ (see Experimental section). Then, the $\mathrm{pH}$ is progressively increased 
through the slow dissolution of $\mathrm{NH}_{3}$ vapours into the reactants solution as illustrated by the color evolution in the presence of few drops of a universal indicator added in the solution (see video S4, Fig.S4). The final cHAp product is obtained after 6 days of reaction.

In the following, we take advantage of the both analytical techniques, Raman (easy implementation, including under in situ conditions in liquid medium thanks to the use of fiber optic Raman probe) and ${ }^{31} \mathrm{P}$ ssNMR (identification, quantification) to monitor cHAp precipitation. Indeed, the sensitivity of Raman spectroscopy allows the recording of successive spectra at short time intervals and thus the in situ study of CaP minerals formation. ${ }^{12,31,63}$ Due to our synthesis protocol, the originality of the present in situ Raman set-up relies on the fact that the Raman probe is directly immersed into the reacting solution (Fig. S1). Hence, the conversion of CaP precursors into biomimetic cHAp is continuously monitored. Complementary, at relevant time points identified thanks to in situ Raman, ex situ ${ }^{31} \mathrm{P}$ ssNMR analysis were used as "analytical snapshots" to complement the identification and quantification of the CaP phases. Selected Raman and ${ }^{31} \mathrm{P}$ ssNMR spectra are displayed in Fig. 4a and Fig. 4b, respectively. 


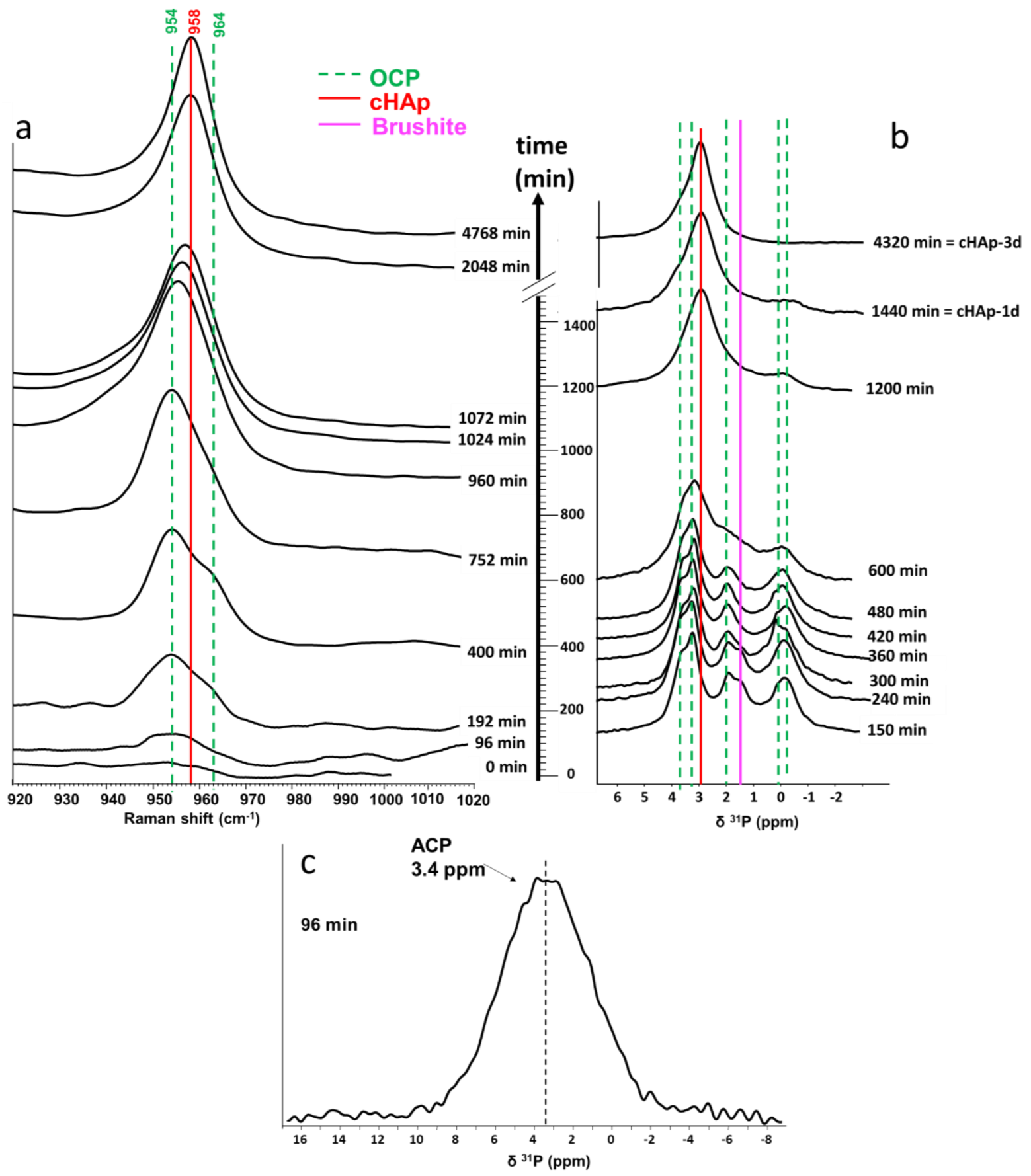

Figure 4. The precipitation of biomimetic apatite is monitored using a combination of (a) in situ Raman and (b). ex situ ${ }^{31} P$ single pulse MAS ssNMR. Green doted lines, red solid line and pink solid line represent the $O C P$, the apatite and the brushite contributions, respectively. (c) ${ }^{31} P C P$ MAS NMR spectrum recorded at $96 \mathrm{~min}$. 


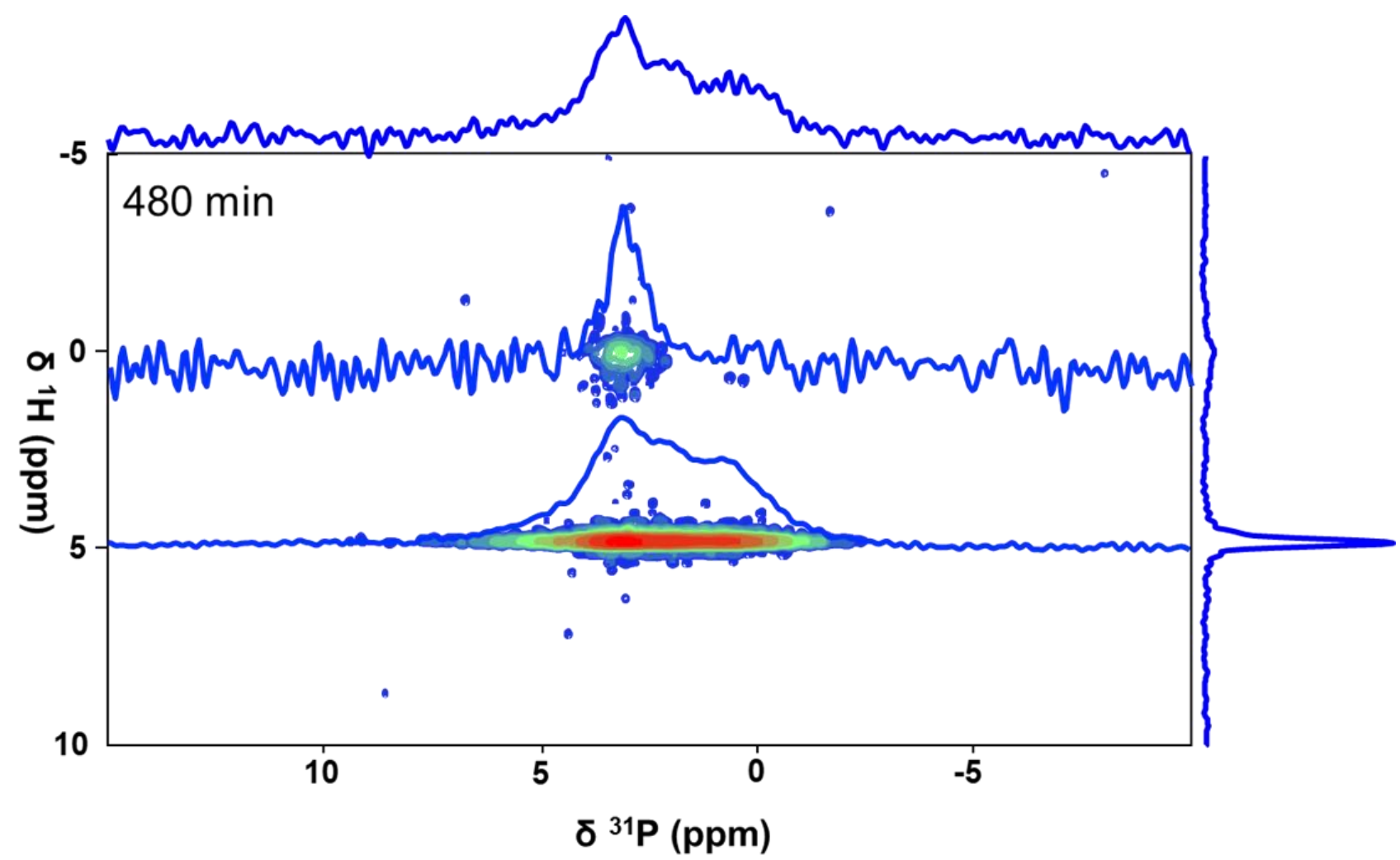

Figure 5: $2 D^{1} \mathrm{H}_{-}^{31} \mathrm{P}$ HetCor experiment (1 ms contact time) recorded after $480 \mathrm{~min}$. together with ${ }^{31} \mathrm{P}$ $1 D$ spectra extracted at $\delta\left({ }^{1} \mathrm{H}\right)=0 \mathrm{ppm}\left(\mathrm{OH}^{-}\right.$from $\left.\mathrm{cHAp}\right)$ and $\delta\left({ }^{1} \mathrm{H}\right)=5 \mathrm{ppm}$ (water molecules from $\mathrm{OCP}$ ).

Table 2. Evolution of the positions and FWHM of the main Raman band upon reaction time

\begin{tabular}{lccc}
\hline $\begin{array}{l}\text { Time } \\
\text { (minutes) }\end{array}$ & Shift $\left(\mathrm{cm}^{-1}\right)$ & FWHM $\left(\mathrm{cm}^{-1}\right)$ \\
\hline 96 & $\sim 954$ & - & - \\
192 & 954 & 964 & 17 \\
400 & 954 & 964 & 17 \\
752 & 954 & 964 & 19 \\
960 & 955 & - & 18 \\
1024 & 956 & - & 14 \\
1072 & 957 & - & 12 \\
2048 & 958 & - & 12 \\
4768 & 958 & - & 11 \\
\hline
\end{tabular}




\section{Formation of amorphous calcium phosphate phase (0-96 min)}

After $96 \mathrm{~min}$, a precipitate forms at the bottom of the flask that displayed a very weak Raman signal around $954 \mathrm{~cm}^{-1}$. The nature of the precipitate is difficult to determine by Raman although it might correspond to a disordered CaP phase ${ }^{10,12,31}$ (Fig. 4a The corresponding ${ }^{31} \mathrm{P}$ single pulse NMR spectrum is not reported in Fig. $\mathbf{4 b}$ due to very low intensity of the related signal. However, the amorphous nature of the precipitate was confirmed by the corresponding ${ }^{31} \mathrm{P} C \mathrm{CP}$ MAS spectrum that exhibits a broad Gaussian line shape (FWHM $\sim 900 \mathrm{~Hz}$ ) centred at $3.4 \mathrm{ppm}$, which is characteristic of an amorphous calcium phosphate phase ${ }^{64}$ (Fig. 4c). This result is consistent with data from the literature showing that apatite precipitation in vitro can involve the formation of an initial disordered phase that subsequently crystalizes into a less soluble and more ordered phase..$^{31,65}$

\section{Formation of brushite and OCP phases $(96-480 \mathrm{~min})$}

Then, as the $\mathrm{pH}$ increases up to 5 value (Video S4, Fig.S4), this unstable ACP progressively transforms into OCP (double Raman band at 954/964 $\mathrm{cm}^{-1}$-see spectrum after 192 minutes, Fig. 4a). The observation of $\mathrm{OCP}$, resulting from the transformation of $\mathrm{ACP}$, as a precursor of apatite is coherent with the literature. ${ }^{11,12,31,66}$ Note that the corresponding Raman bands are slightly broader compared to the reference OCP powder ( $F W H M=19 \mathrm{vs} 15 \mathrm{~cm}^{-1}$ ) suggesting a less crystalline nature. In addition, in these in situ recording conditions, the $\mathrm{S} / \mathrm{N}$ is poor and the $v_{\mathrm{HPO} 4}$ contribution characteristic of OCP (see section 1) expected at $1008 \mathrm{~cm}^{-1}$ is not detected. Ex situ ${ }^{31} \mathrm{P}$ ssNMR confirms that OCP is formed in this time interval as the characteristic ${ }^{31} \mathrm{P}$ chemical shifts of the OCP phase are observed from 150 minutes of reaction (Fig. $\mathbf{4 b}$ ). In accordance with Raman features, broader ${ }^{31} \mathrm{P}$ OCP resonances are observed compared to the OCP reference sample confirming the poorly crystalized nature of OCP formed at this step of the precipitation process. In addition, brushite (DCPD) is observed after $150 \mathrm{~min}$ by ${ }^{31} \mathrm{P}$ ssNMR (characteristic signal at $1.4 \mathrm{ppm}$ ) but is not detected anymore after 300 min (Fig. 4b). Interestingly, this transient phase is not detected by in situ Raman in our conditions (expected 
contribution at $\left.987 \mathrm{~cm}^{-1}\right)^{67}$ but was evidenced as intermediates during ACP to OCP transformation in hanging drop vapor diffusion experiments. ${ }^{31}$

\section{OCP transformation in CHAp (480 min-end)}

According to in situ Raman and ex situ ${ }^{31} \mathrm{P}$ ssNMR, the transformation of OCP into cHAp seems to start long after $480 \mathrm{~min}$. Indeed, the corresponding spectra (in situ Raman after $400 \mathrm{~min}$ and ex situ ${ }^{31} \mathrm{P}$ ssNMR after $480 \mathrm{~min}$ ) still exhibit the characteristic signals of OCP (Fig. 4a,b). However, according to two-dimensional ssNMR experiment $\left({ }^{1} \mathrm{H}-{ }^{31} \mathrm{P}\right.$ HetCor), $\mathrm{cHAp}$ is already present in the medium after $480 \mathrm{~min}$ (Fig.5): if OCP is noticeably highlighted (correlation signal at $\delta\left({ }^{1} \mathrm{H}\right)=5 \mathrm{ppm}$ ), a small amount of $\mathrm{cHAp}$ is also evidenced through the characteristic correlation signal at $\delta\left({ }^{1} \mathrm{H}\right)=0 \mathrm{ppm}$.

The transformation of OCP into $\mathrm{CHAp}$ is becoming evident on one-dimensional spectra starting from 752 min as shown by the modification of the Raman signal shape (Fig. 4a). If the maximum of the $v_{1} \mathrm{PO}_{4}$ band from OCP is still detected at $954 \mathrm{~cm}^{-1}$ up to $960 \mathrm{~min}$, the associated shoulder at $964 \mathrm{~cm}^{-1}$ is not clearly observed after $752 \mathrm{~min}$ (Table 2). This is significant of a growing contribution at $958 \mathrm{~cm}^{-1}$ related to the formation of cHAp. Then, the band maximum is progressively shifted to higher wavenumber, finally reaching $958 \mathrm{~cm}^{-1}$ (typical value of cHAp) after 1072 min of reaction.

Ex situ ${ }^{31} \mathrm{P}$ ssNMR provides complementary data on the temporal evolution of OCP transformation into cHAp. In accordance with Raman data, we observe a strong modification of the ${ }^{31} \mathrm{P}$ OCP resonances after $600 \mathrm{~min}$. First, the ${ }^{31} \mathrm{P}$ OCP linewidths increase suddenly after $600 \mathrm{~min}$, then, the maximum of the ${ }^{31} \mathrm{P}$ signal is shifted to reach the characteristic value of $\mathrm{cHAp}\left(\delta\left({ }^{31} \mathrm{P}\right)=2.8 \mathrm{ppm}\right)$ after $1200 \mathrm{~min}$. The enlargement of the resonances indicates a deep modification of the OCP structure through the increase of the local disorder around the phosphate sites upon cHAp formation. However, the transformation of OCP into CHAp is not fully accomplished after $1440 \mathrm{~min}$ as the characteristic resonances of $\mathrm{P} 3, \mathrm{P} 5, \mathrm{P} 5$ sites around $0 \mathrm{ppm}$ are still visible on the ${ }^{31} \mathrm{P}$ ex situ ssNMR spectra. The 
transformation seems to be fully completed after $2048 \mathrm{~min}$ (Raman data: $v_{1} \mathrm{PO}_{4}=958 \mathrm{~cm}^{-1}$ ) and is confirmed by ${ }^{31} \mathrm{P}$ ssNMR after $4320 \mathrm{~min}$ (3 days of reaction).

According to the calibration curve obtained from the OCP/cHAp physical mixtures (Fig. S3b), and spectral decomposition (Fig S5) the OCP weight proportion is estimated to 45,26 and 16 wt\% ( \pm 10) at 600,1200 and 1440 min, respectively. Note however, that decomposition of the spectra is not as accurate as in the case of physical mixture, due to the broadening and shifting of some OCP ${ }^{31} \mathrm{P}$ resonances. Especially the contributions at low chemical shift that are characteristic of the phosphates located in the hydrated layer of OCP are not accurately simulated. This strongly suggests a modification of the OCP structure along the precipitation route, as investigated below.

To sum up this study, cHAp precipitation in our conditions starts with the formation of ACP that turns into OCP (and brushite) and finally into $\mathrm{CHAp}$. Such a sequence of formation of brushite and OCP $\left(\mathrm{pH}^{\sim 5}\right)$, then of $\mathrm{cHAp}\left(\mathrm{pH}^{\sim 9}\right.$ ) (Fig. S4) is consistent with what is expected from the speciation diagram of phosphate ions in solution. ${ }^{68}$ Such evolution of ACP into $\mathrm{cHAp}$ through transient OCP formation was already reported, but either through ex situ Raman measurements ${ }^{12}$ that implied washing steps that might have led to some changes in the chemical nature of the precipitates or under specific conditions (hanging drops vapor diffusion system) ) $^{31}$ that are representative of tiny amounts of matter and may induce different precipitation kinetics. Here, in situ Raman spectroscopy avoids these misleading experimental features, but it appears to be less sensitive compared to ssNMR to precisely identify cHAp at early stage of formation and residual OCP in presence of cHAp. This emphasizes the advantage to combine in situ and ex situ sensitive spectroscopic technics to detect OCP in small amount in the course of its transformation into cHAp. Moreover, the recording of $2 \mathrm{D}{ }^{31} \mathrm{P}$ HetCor NMR experiments appears useful to track the early stages of $\mathrm{cHAp}$ formation. We also note that the OCP phase persists up to 1440 min (i.e. 1 day) of reaction. Thus, OCP can be considered as a potential contaminant phase of cHAp in our conditions of precipitation. Using in situ Raman and ex situ ${ }^{31} \mathrm{P}$ 
ssNMR, the determination and quantification of this potential contaminant phase $(\leq 10 \%)$ is particularly difficult. Other analytical techniques might be used to access tiny amount of OCP.

\subsection{Pushing up the detection limit of ssNMR by cross polarization}

Many apatites obtained by precipitation likely to mimic biological apatites involve the formation of OCP. $6,10,11$ Hence, OCP resulting from the incomplete transformation into carbonated apatite may exist as a persistent phase in the final material although not detected. In our conditions, the complete transformation of OCP into $\mathrm{CHAp}$ is achieved after 6 days. Hence, samples obtained after 1,2 and 3 days (cHAp-1d, cHAp-2d and cHAp-3d, respectively) i.e. before total completion of cHAp precipitation are likely to contain low amounts of OCP. If after 1 day of reaction (1440 $\mathrm{min}$ ) $16 \pm 10 \mathrm{wt} \%$ of OCP in cHAp-1d are estimated by ${ }^{31}$ P ssNMR (Fig. S3b, Fig. S5), after 3 days (4320 min) both Raman and ${ }^{31} \mathrm{P}$ ssNMR failed to detect traces of OCP in cHAp-3d.

In order to push up the detection limit of OCP, cHAp-1d, cHAp-2d, cHAp-3d and cHAp samples were analyzed by ${ }^{1} \mathrm{H}-{ }^{3} 1 \mathrm{P}$ CP MAS NMR (Fig. 6). Although non quantitative, ${ }^{1} \mathrm{H}-{ }^{31} \mathrm{P}$ CP MAS NMR is much more sensitive than ${ }^{31} \mathrm{P}$ single pulse experiments to protonated phosphates.

As a consequence, ${ }^{31} \mathrm{P}$ resonances of phosphates within the OCP structure in protonated environments (P2 and P3, P5, P6 signing at $\delta\left({ }^{31} \mathrm{P}\right)=1.7$ and $-0.3 \mathrm{ppm}$, respectively) are highlighted at short contact time (1 ms) (Fig.6). It clearly confirms that the OCP transformation into cHAp is totally achieved after 6 days in our conditions. Conversely, OCP is still present as a contaminant phase up to 3 days of reaction (i.e. in cHAp-1d, cHAp-2d and even in cHAp-3d). 


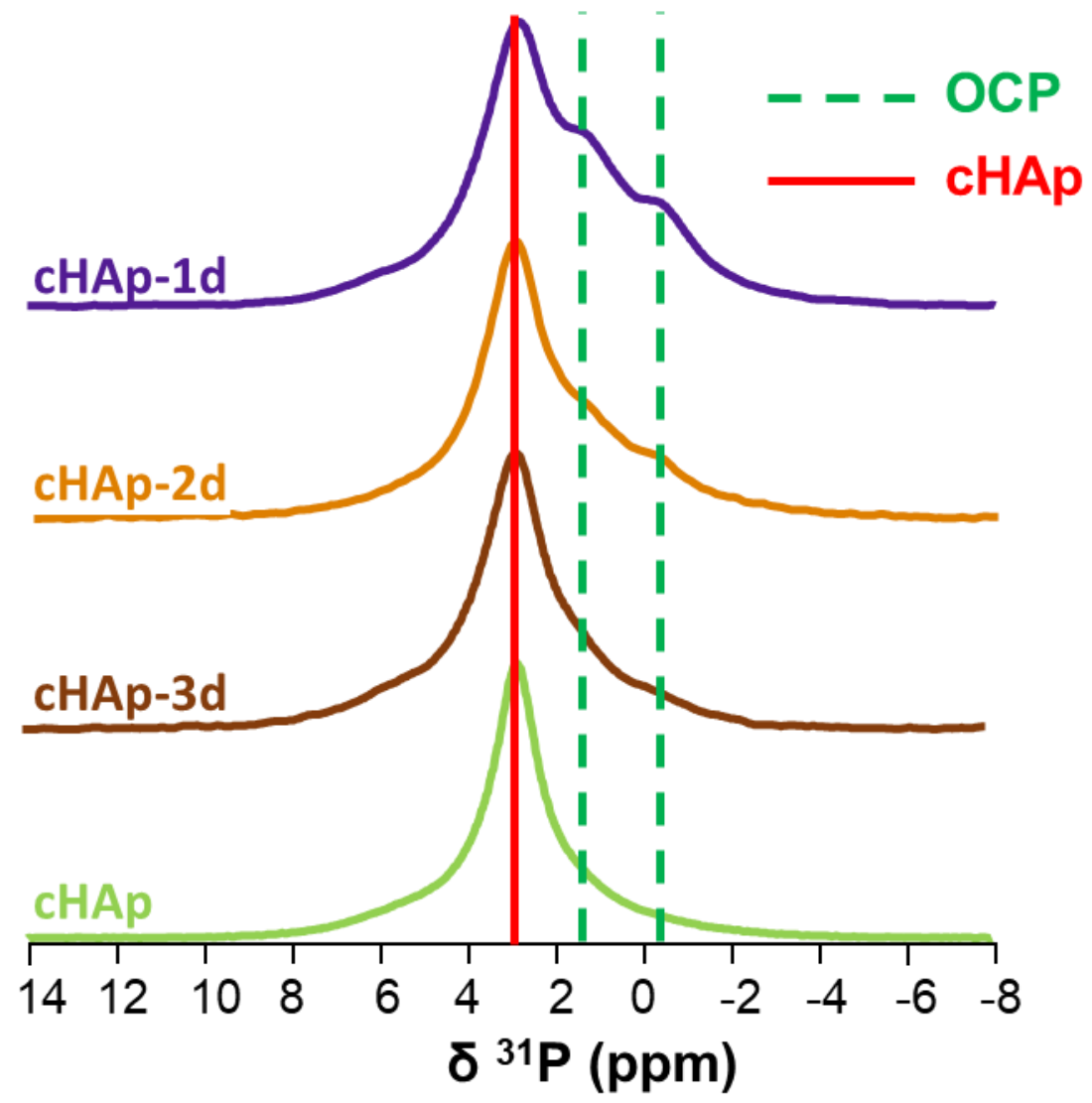

Figure 6. ${ }^{1} \mathrm{H}-{ }^{31} \mathrm{P} C P$ MAS (contact time $=1 \mathrm{~ms}$ ) spectra of $\mathrm{CHAp}-1 \mathrm{~d}$, $\mathrm{CHAp}-2 \mathrm{~d}$, $\mathrm{CHAp}-3 \mathrm{~d}$ (incomplete OCP to $C H A p$ transformation) and CHAp (reference sample). Red full line and green dotted lines represent the ${ }^{31} P$ resonances of $C H A p$ and $O C P\left(P 2\right.$ and $P 3, P 5, P 6$, according to Davies et al. $\left.{ }^{44}\right)$, respectively.

\subsection{Structural and quantitative investigations of residual OCP using XRPD and Rietveld refinement}

The use of X-ray diffraction to determine the presence of a minor phase of OCP along with CHAp is also challenging, because most of the reflections from these two crystalline phases overlapped within the angular range $(2 \theta)$ of $10^{\circ}-60^{\circ}$. Moreover, the diffraction peaks broadening due to nanometric coherent domain sizes increases this difficulty (Fig. 7). To overcome these difficulties, the low angular range (20) of $4^{\circ}-10^{\circ}$ was considered since three reflections are specific to OCP: Bragg peak (100) at $2 \theta=4.7^{\circ}$, ( $1 \overline{1} 0$ ) at $9.5^{\circ}$ and (010) at $9.8^{\circ}$, with the following relative intensities : $100 \%, 8 \%$ and $8 \%$, respectively (see PDF card number 01-079-0423 and ICSD data \#65347). This low angular region is rarely available on apatite diffraction patterns reported in the literature because this region is rarely analysed on 
conventional diffractometers. From Fig. 7, inset, the presence of OCP is unambiguously confirmed in cHAp- $1 \mathrm{~d}$ and $\mathrm{cHAp}-2 \mathrm{~d}$ thanks to the detection of peaks in the $3-10^{\circ} 2 \theta$ region, but the case of cHAp$3 \mathrm{~d}$ is more questionable on this sole basis.

We performed Rietveld refinement analysis on XRPD data collected from these different cHAp samples. Beforehand, the OCP crystal structure (firstly resolved by Brown, ${ }^{39}$ and further improved by a single crystal study by Mathew et al. ${ }^{40}$ ) was checked on the pure OCP phase (reference sample). The adequacy between our synthetic OCP sample and the $\mathrm{Ca}_{8}\left(\mathrm{HPO}_{4}\right)_{2}\left(\mathrm{PO}_{4}\right)_{4} \cdot 5 \mathrm{H}_{2} \mathrm{O}$ model crystal structure $e^{40}$ is shown by comparison of the cell parameters reported in Table S6. The refined preferential orientation allowed the adequate modeling of the experimental OCP powder pattern as seen on Figure S6 and expressed by good Rietveld agreement factors (Table S6). This is significant of the platelet crystal growth in the [100] direction which overexposed the intense (100) diffraction peak. Such a platelet morphology coherent domain is explained by the layered structure of OCP displaying alternatively "apatitic layers" and 'hydrated layer' along the $a$ axis as shown in Fig. S7. 


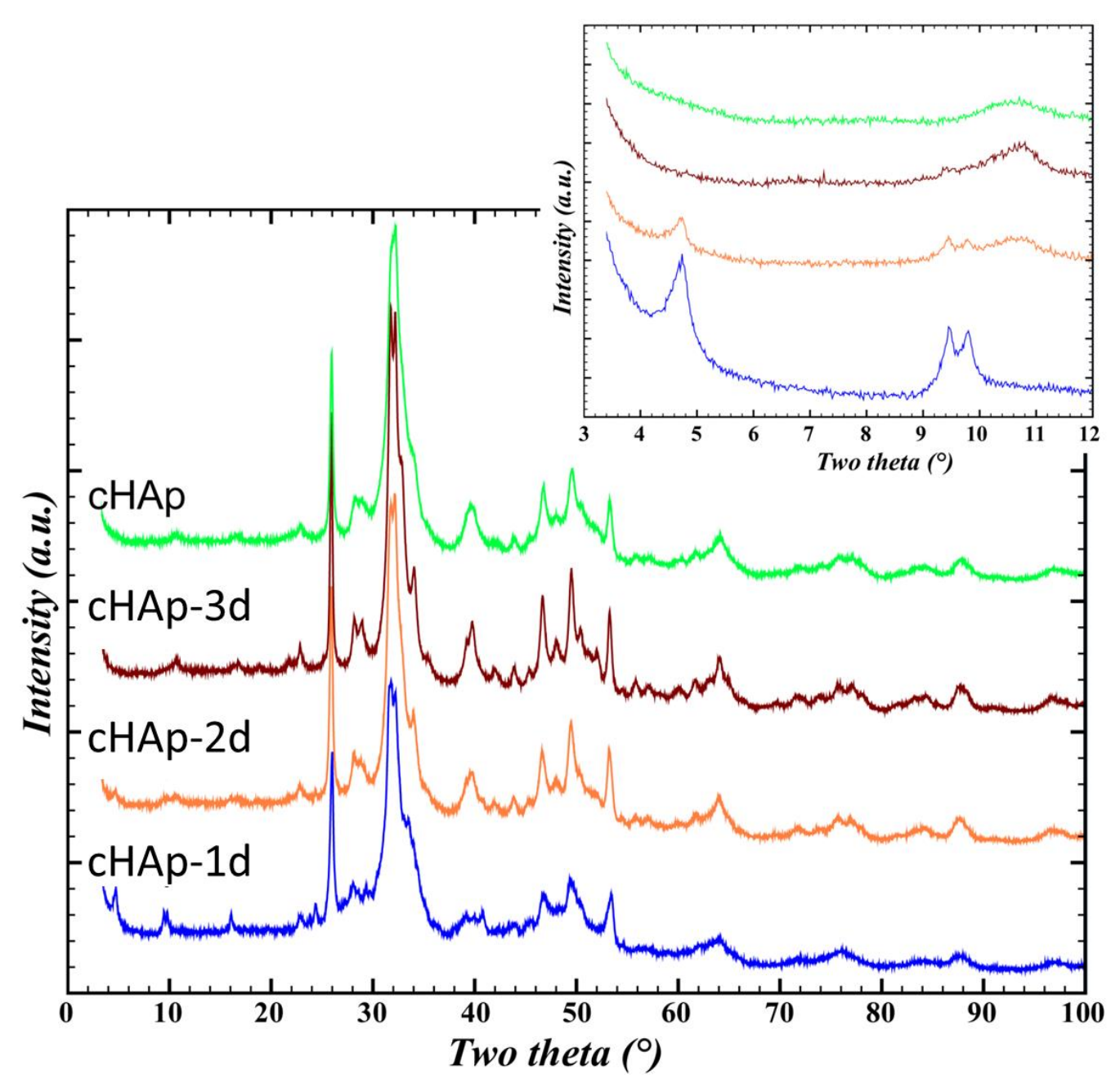

Figure 7. X-ray diffraction powder patterns of cHAp-1d, cHAp-2d and cHAp-3d (powders containing OCP as a contaminant phase) and CHAp. The inset shows the zoom in the $3.5-12^{\circ} 2 \theta$ range.

Rietveld refinements were undertaken in order to determine the relative proportions of $\mathrm{OCP} / \mathrm{cHAP}$ present in $\mathrm{cHAp}-1 \mathrm{~d}, \mathrm{cHAp}-2 \mathrm{~d}$ and $\mathrm{cHAp}-3 \mathrm{~d}$ samples. Surprisingly, compared to what is found for the reference OCP sample (Fig. S6), in the case of $\mathrm{CHAp}-1 \mathrm{~d}$ and $\mathrm{CHAp}-2 \mathrm{~d}$ the intensity of the OCP (100) diffraction peak at $4.7^{\circ} 2 \theta$ is strongly reduced in comparison with that of the $(1 \overline{1} 0)$ and $(010)$ peaks $\left(9.5^{\circ}, 9.8^{\circ}\right.$, respectively) (Fig. 7 inset). Preferential orientation correction was considered, but was insufficient to model accordingly the relative intensity of the first diffraction peak. Thus, we assume that such a decrease of the relative intensity of the (100) diffraction peak is indicative of a modification of the OCP structure during the transformation into cHAp. To further investigate this 
assumption, the variation of the electronic density in the OCP hydrated layer was simulated (Fig. S8; the electron density being formally transposed to an equivalent number of water molecules). We observe that increasing the electronic density in the interlayer space results in a significant decrease of the relative intensity of the (100) diffraction peak (compared to the pure OCP structure $\left.\mathrm{Ca}_{8}\left(\mathrm{HPO}_{4}\right)_{2}\left(\mathrm{PO}_{4}\right)_{4} \cdot 5 \mathrm{H}_{2} \mathrm{O}\right)$ whereas the intensity of other diffraction peaks were not strongly impacted, in particular the $(1 \overline{1} 0)$ and (010) peaks. These simulations suggest that the OCP phase transforming into cHAp may undergo an alteration of its hydrated layer structure involving the incorporation of species with higher electronic density, compared to that present in the reference OCP structure. Such a modification of the hydrated layer as the $\mathrm{pH}$ increases suggests an hydrolysis mechanism of the OCP transformation into $\mathrm{cHAp}$, which is also supported by the thin platelets morphology of the final cHAp sample. ${ }^{50}$ Indeed, dissolution/precipitation or epitaxial mechanism (i.e. growth of cHAp over OCP) should rather induce the formation of crystals of different morphologies: rods with hexagonal section and thick platelets, respectively.

Rietveld refinements of the cHAp-1d, cHAp-2d and cHAp-3d samples were thus done combining the effects of preferential orientation and increase of the electronic density inside the hydrated layer of the OCP structure. Almost doubling the latter parameter was found decisive to get accurate Rietveld refinements (Fig. 8) resulting in good Rietveld agreement factors (Table 3), and thus allows the quantification of the two phases. As reported in Table 3; the OCP content progressively decreased over maturation time, and was estimated to be $15 \mathrm{wt} \%, 5 \mathrm{wt} \%$ and $2 \mathrm{wt} \%$ for cHAp- $1 \mathrm{~d}$, cHAp-2d and cHAp-3d, respectively. Note that compositions obtained by Rietveld refinements and solid state NMR (based on calibration curve) for the cHAp-1d and the cHAp after 1440 min of reaction (1day), 15 and 16 wt \%, respectively, are in very good accordance. The decreasing linewidth of XRD reflections from cHAp-1d to $\mathrm{cHAp}-3 \mathrm{~d}$ (Fig. 8 b) indicates the increase in crystallinity of the related apatite phase upon reaction time. This is in good concordance of the cell parameters obtained for $\mathrm{CHAp}$ with those previously reported ${ }^{55,56}$ and explains the slight improvement of the reliability factors from cHAp-1d to $\mathrm{cHAp}-3 \mathrm{~d}$. Moreover, as illustrated by the increasing cell volume of the OCP with ageing 
time, the OCP structure is altered during the transformation from OCP to $\mathrm{CHAp}$ in agreements with previous results where OCP lattice parameters were found to increase in the stage preceding OCP conversion to apatite. ${ }^{69}$
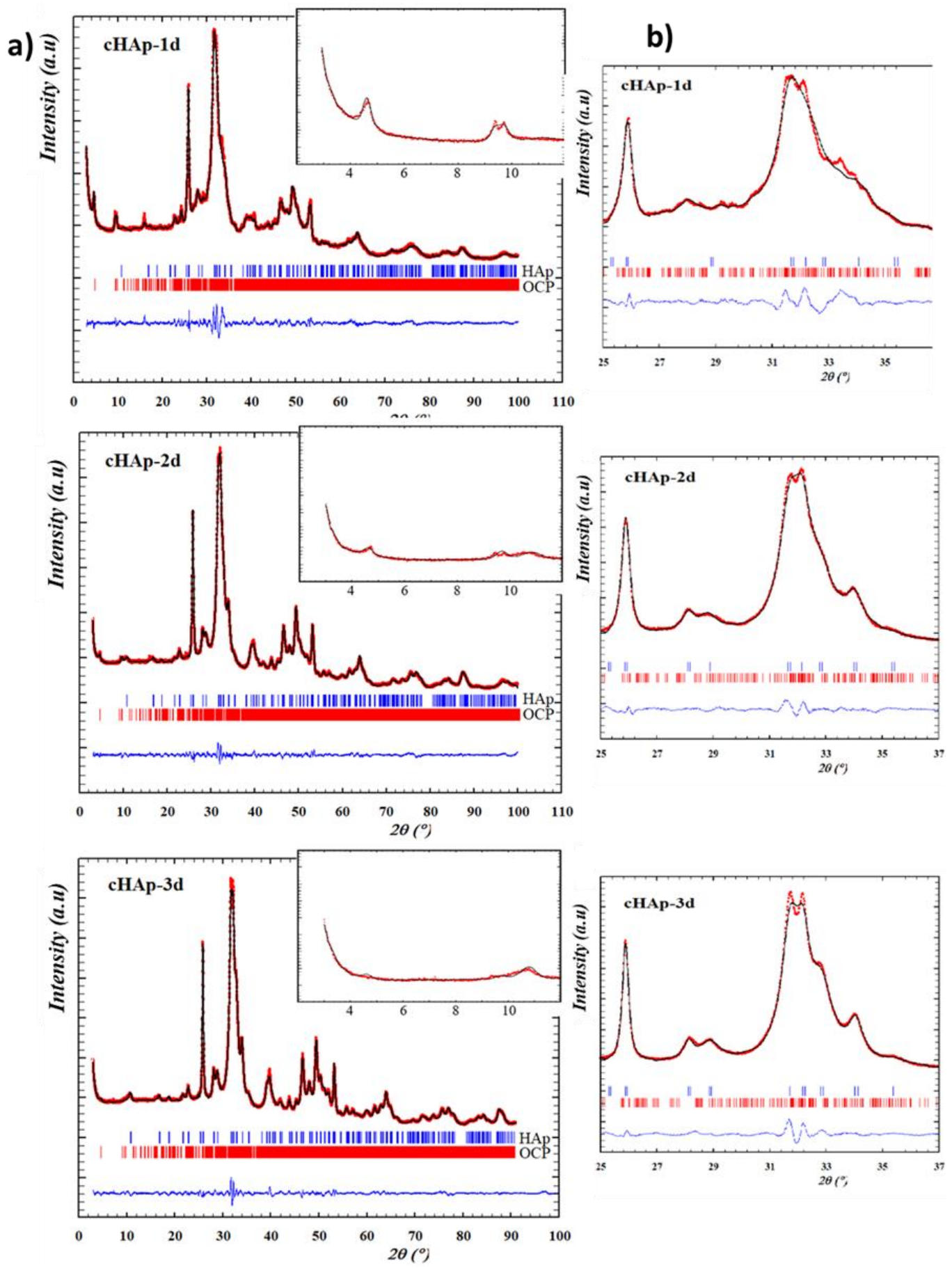

Figure 8: XRD patterns and Rietveld refinements ofcHAp-1d, cHAp-2d and cHAp-3d allowing the extraction of the OCP/CHAp relative proportions. Red point for experimental measurement, black line for calculated pattern assuming an increase of the electronic density in the OCP hydrated layers (see 
Table 3 and discussion in the text), blue line for difference curve and blue and red sticks for OCP and HAp Bragg positions, respectively. (a)in the full 0-100 $2 \theta\left(^{\circ}\right)$ range and zoom in the 0-12 $2 \theta\left(^{\circ}\right)$ range in the insets(b) zoom in the 25-37 $2 \theta\left(^{\circ}\right)$ range. 
Table 3 : Quantitative analysis and structural properties of CHAp and OCP phases present in cHAp-1d, cHAp-2d and cHAp-3d deduced from Rietveld refinements. The electronic density in the OCP hydrated layer is expressed as two composition limits associated with an equivalent number of water molecules or carbonate ions. Standard deviations are indicated in bracket.

\begin{tabular}{|c|c|c|c|c|c|c|}
\hline \multirow{2}{*}{ sample } & \multirow{2}{*}{$\begin{array}{l}\text { Rietveld } \\
\text { agreement } \\
\text { factors }\end{array}$} & \multicolumn{2}{|c|}{ cell parameters } & \multicolumn{2}{|c|}{$\begin{array}{c}\text { Assignment of the electronic density in the } \\
\text { hydrated layer of the OCP phase in } \\
\text { equivalent number of }\end{array}$} & \multirow{2}{*}{$\begin{array}{l}\text { Quantitative analysis } \\
\text { HAp / OCP }\end{array}$} \\
\hline & & cHAp & OCP & $\mathrm{H}_{2} \mathrm{O}$ molecules & $\mathrm{CO}_{3}{ }^{2-}$ ions & \\
\hline cHAp-1d & $\begin{array}{l}\operatorname{Rp}(\%)=7.63 \\
\operatorname{Rwp}(\%)=9.30 \\
\chi^{2}=7.80\end{array}$ & $\begin{array}{l}a=9.440(3) \AA \\
c=6.893(2) \AA\end{array}$ & $\begin{array}{l}a=19.692(9) \AA \\
b=9.489(4) \AA \\
c=6.8624(4) \AA \\
\alpha=90.12(1)^{\circ} \\
\beta=92.16(1)^{\circ} \\
\gamma=108.23\left(3^{\circ}\right) \\
V=1216.9(7) \\
\AA^{3}\end{array}$ & $9(1)$ & $2.8(3) \mathrm{CO}_{3}^{2-}$ & $85(3) / 15(3)$ \\
\hline cHAp-2d & $\begin{array}{l}\operatorname{Rp}(\%)=5.52 \\
\operatorname{Rwp}(\%)=5.97 \\
\chi^{2}=5.94\end{array}$ & $\begin{array}{l}a=9.4590(9) \AA \\
c=6.8833(6) \AA\end{array}$ & $\begin{array}{l}a=20.189(2) \AA \\
b=9.4451(4) \AA \\
c=6.8540(3) \AA \\
\alpha=90.354(3)^{\circ} \\
\beta=92.680(6)^{\circ} \\
\gamma=105.843(6)^{\circ} \\
V=1257.2(1) \\
\AA^{3}\end{array}$ & $8(1)$ & $2.5(3) \mathrm{CO}_{3}^{2-}$ & $95(2) / 5(2)$ \\
\hline
\end{tabular}




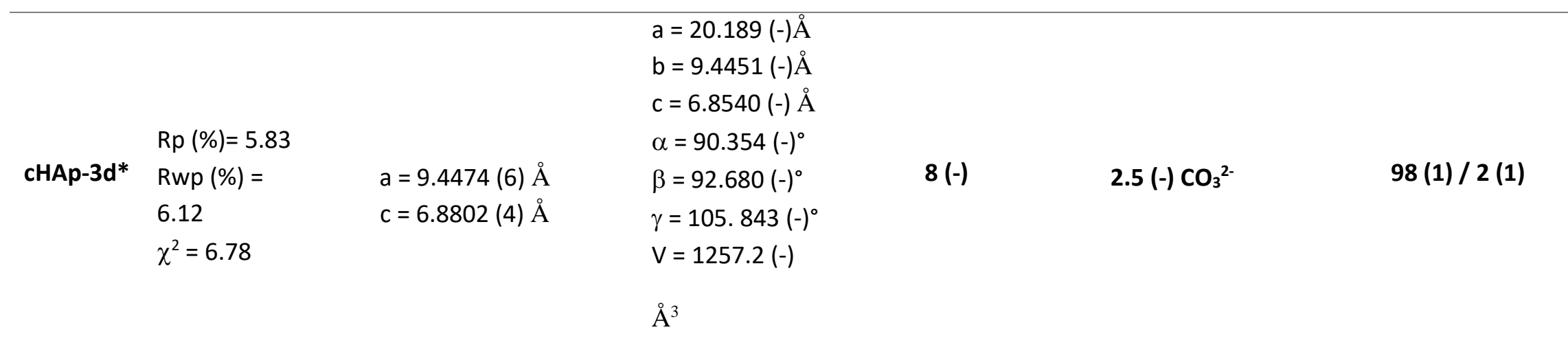

* Lattice parameters of the OCP phase in the cHAp-3d sample have been fixed to the values previously refined for the cHAp-2d sample (because of too weak amount of the phase - about $2 \mathrm{wt} \%$ - to refine lattice parameters of a triclinic phase).

$\$$ transcription of the electronic density into an equivalent number of water molecules (10 electrons par $\mathrm{H}_{2} \mathrm{O}$ molecule) or carbonate ions ( 32 electrons par $\mathrm{CO}_{3}{ }^{2-}$ ) 
Accordingly, OCP phases in these samples exhibit a significant higher electronic density compared to the OCP reference structure possessing 5 water molecules per unit cell within the hydrated layers. Such an increase in the electronic density might be ascribed to the incorporation of additional water molecules (Table 3). Indeed, according to Tseng et $a I^{13}$ the transformation of OCP into $\mathrm{CHAp}$ is controlled by OCP hydrolysis through the incorporation of water molecules into the hydrated layers leading to the deprotonation of the $\mathrm{HPO}_{4}{ }^{2-}$ ions via the basic hydrolysis reaction $\mathrm{HPO}_{4}{ }^{2-}$ $+\mathrm{OH}^{-}=\mathrm{PO}_{4}{ }^{3-}+\mathrm{H}_{2} \mathrm{O}$. Such mechanism is consistent with our synthesis set-up where the $\mathrm{pH}$ of the solution is around 10 after 1 day of reaction ( $\mathbf{S 4}$ video). Thus the increase in electronic density may be tentatively ascribed to an increase in number of water molecules. Hence, if we express the electronic density as an equivalent number of water molecules, we found between 8 (OCP in cHAp-2d and cHAp3d) and 9 (OCP in cHAp-1d) equivalent water molecules, largely exceeding the 5 molecules associated to the full occupancy factors in the OCP structure. However, it is questionable if the steric hindrance associated with such high hydration level within the OCP structure is compatible with the preservation of the whole structural organization shown by the absence of impact on the other diffraction peaks of the OCP structure (Fig. 8).

Thus, one may alternatively consider the possible incorporation of species with higher electronic density than water to account for the increase of electronic density within the hydrated layer. Indeed, it was reported that citrate, succinate or carbonate ions can be incorporated in the OCP structure, affecting the scattering contrast between apatitic and hydrated layers, and then the (100) peak relative intensity. ${ }^{43,70,71}$ In the present study, given that the final apatite phase is carbonated, the involvement of carbonate ions should also be considered. The two composition limits assuming the involvement of only water ( 9 to 8 molecules) or only carbonates ( 2.6 to 2.3 ions) are present are reported in Table 3, even though a mixed water-carbonate composition is much rather expected. The charge balance compensation required upon carbonate incorporation could be easily achieved through the propensity of phosphate towards protonation. Such carbonate uptake within OCP 
hydrated layers is relevant considering that the mechanism of incorporation of carbonate upon of OCP transformation into carbonated apatite still remains an open question. 


\section{Conclusion}

The present study provides a suitable and relevant methodology to monitor cHAp precipitation from the identification and quantification of mineral precursor phases to their mechanism transformation into cHAp. The advantages and limitations of Raman and ssNMR spectroscopies are discussed in a context of the uncertain qualitative discrimination and quantification of OCP and cHAp, especially for low OCP relative content. From comparative study performed on physical mixtures of OCP and cHAp compounds, the better resolved contributions of the OCP from the cHAp ones in ${ }^{31} \mathrm{P}$ NMR compared to Raman makes this technic more sensitive to visually detect the characteristic fingerprints of OCP. However, providing Raman spectral decomposition is achieved or the weak $\mathrm{vHPO}_{4}$ contribution at $1008 \mathrm{~cm}^{-1}$ is tracked, both techniques finally enable to successfully qualitatively detect down to $10 \%$ OCP mixed in CHAp, even though only ssNMR allows accurate quantification thanks to calibration curve. Despite its detection limitation, Raman can be advantageously carried out under in situ conditions thanks to the use of fiber optic Raman immersion probe. It provides thus a unique opportunity to monitor without any perturbation the kinetics of precipitation of cHAp. Such in situ Raman study allowed tracking relevant time points to complementary better identify by solid state NMR the sequential formation of the calcium phosphate phases transiently formed in the course of biomimetic $\mathrm{cHAp}$ precipitation. Consistently with the progressive increase of the $\mathrm{pH}$, induced by the slow dissolution of $\mathrm{NH}_{3}$ vapor in the reactants solution, ACP is first identified after 96 min thanks to solid state NMR and then it progressively transforms to poorly crystalline $\mathrm{OCP}$, that is detected from from 150 min and 192 min by solid state NMR and Raman, respectively. Although detected by solid state NMR the transient formation of Brushite (150-300 min) is not clearly identified by in situ Raman. If OCP is still present after 480 min, according to $2 \mathrm{D}$ HetCor NMR experiment, its transformation into cHAp has already started. This slow transformation leads to progressive modification of the shape of the Raman and solid state NMR signals. The maximum of the main $\mathrm{vPO}_{4}$ Raman band is progressively shifted and reaches $958 \mathrm{~cm}^{-1}$ that is typical of cHAp from $1072 \mathrm{~min}$. However, according to solid state NMR, the transformation still goes on with still detectable contributions of OCP, estimated to $16 \mathrm{wt} \%$, 
up to $1440 \mathrm{~min}$. Although not quantitative, the highly sensitive ${ }^{1} \mathrm{H}^{31} \mathrm{P} C P$ MAS NMR sequence confirms that the OCP transformation is achieved after 6 day of reaction, and evidences that residual OCP is still present after 3 days. Thus, coupling in situ Raman and ex situ ssNMR spectroscopies provides a very interesting tool to track and quantify OCP during its transformation into cHAp. Complementary, final cHAp powders can be advantageously characterized by XRD and the quantification limit encountered with solid state NMR can be overcome through Rietveld refinements. It allowed to detect the persistence of OCP as contaminant phase still present down to $2 \mathrm{wt} \%$ after 3 days of reaction. To reach accurate refinements, the abnormal evolution of the $2 \theta=4.7^{\circ}$ line of OCP phase undergoing transformation into $\mathrm{cHAp}$ has to be simulated by increasing the electronic density of the hydrated layer of OCP occurring in the course of its transformation into cHAp. It is rationalized by the incorporation of additional water molecules and/or to carbonate uptake within the hydrated layer of the OCP structure. These two types of transient structural modifications are relevant in the context of the transformation of OCP to carbonated CHAp, and could be associated to the undergoing OCP hydrolysis and to the carbonation mechanism of $\mathrm{CHAp}$ from OCP, respectively.

\section{Acknowledgement}

This work was supported by French state funds managed by the ANR within the Investissements d'Avenir program under reference ANR-11-IDEX-0004-02, and more specifically within the framework of the Cluster of Excellence MATISSE led by Sorbonne Université. The authors are also grateful to Vincent Losinho from Laboratoire Réactivité de Surface, Sorbonne Université for his involvement in the implementation of the in situ Raman set up.

\section{Electronic Supplementary Information Available:}

(S1) Schematic representation of the in situ Raman set-up. 
(S2) Decomposition of the $v_{1} \mathrm{PO}_{4}$ region of the Raman spectra of pure OCP, CHAP and physical mixtures of the two compounds.

(S3) Decomposition of the ${ }^{31} \mathrm{P}$ NMR spectra of pure OCP, CHAP and physical mixtures of the two compounds and deduced calibration curve.

(S4) Biomimetic apatite precipitation visualized via video (web enhanced object) and pictures recorded in the presence of universal indicator solution.

(S5) Decomposition of the ${ }^{31} \mathrm{P}$ NMR spectra recorded during the precipitation of biomimetic apatite.

(S6) Rietveld refinement of the prepared OCP sample showing concluding to the adequacy with the OCP structure model.

(S7) Representation of the OCP structure.

(S8) Rietveld simulations accounting for the modification of the intensity of the (100) diffraction line of OCP.

References

1. C. Drouet, BioMed Res. Int., 2013, 2013, 1-12.

2. C. Combes, S. Cazalbou and C. Rey, Minerals, 2016, 6, 34.

3. C. Rey, C. Combes, C. Drouet, H. Sfihi and A. Barroug, Mat. Sci. Eng. C-Biomim., 2007, vol. 27 (n²) 198-205.

4. C. Rey, C. Combes, C. Drouet and M. J. Glimcher, Osteoporos Int., 2009, 20, 1013-1021.

5. Y. Wang, S. Von Euw, F. M. Fernandes, S. Cassaignon, M. Selmane, G. Laurent, G. PehauArnaudet, C. Coelho, L. Bonhomme-Coury, M. M. Giraud-Guille, F. Babonneau, T. Azaïs and N. Nassif, Nat. Mater., 2013, 12, 1144-1153.

6. M. S.-A. Johnsson and G. H. Nancollas, Crit. Rev. Oral Biol. Med, 1992, 3, 61-82.

7. L. Wang and G. H. Nancollas, Chem. Rev., 2008, 108, 4628-4669.

8. A. Dey, P. H. H. Bomans, F. A. Müller, P. M. Frederik, G. de With and N. A. J. M. Sommerdijk, Nat. Mater., 2010, 9, 1010-1014.

9. G. He, T. Dahl, A. Veis and A. George, Nat. Mater., 2003, 2, 552-558.

10. G. R. Sauer, W. B. Zunic, J. R. Durig and R. E. Wuthier, Calcif Tissue Int 1994, 54, 414-420.

11. W. J. E. M. Habraken, J. Tao, L. J. Brylka, H. Friedrich, L. Bertinetti, A. S. Schenk, A. Verch, V. Dmitrovic, P. H. H. Bomans, P. M. Frederik, J. Laven, P. van der Schoot, B. Aichmayer, G. de With, J. J. DeYoreo and N. A. J. M. Sommerdijk, Nat. Commun., 2013, 4, 1507.

12. M. Kazanci, P. Fratzl, K. Klaushofer and E. P. Paschalis, Calcif. Tissue Int., 2006, 79, 354-359. 
13. Y. H. Tseng, C. Y. Mou and J. C. C. Chan, J. Am. Chem. Soc., 2006, 128, 6909-6918.

14. N. J. Crane, V. Popescu, M. D. Morris, P. Steenhuis and M. A. J. Ignelzi, Bone, 2006, 39, 434442.

15. P. Bodier-Houlle, P. Steuer, J. C. Voegel and F. J. Cuisinier, Acta Cryst., 1998, D54, 1377-1381.

16. E. Gentleman, R. J. Swain, N. D. Evans, S. Boonrungsiman, G. Jell, M. D. Ball, T. A. V. Shean, M. L. Oyen, A. Porter and M. M. Stevens, Nat. Mater., 2009, 8, 763-770.

17. F. Nudelman, P. H. H. Bomans, A. George, G. de With and N. A. J. M. Sommerdijk, Faraday Discuss., 2012, 159, 357-370.

18. F. Castro, A. Ferreira, F. Rocha, A. Vicente and J. Teixeira, Chem. Eng. Sci., 2012, 77, 150-156.

19. T. Tsuji, K. Onuma, A. Yamamoto, M. lijima and K. Shiba, P Natl. Acad. Sci. USA, 2008, 105, 16866-16870.

20. A. Lotsari, A. K. Rajasekharan, M. Halvarsson and M. Andersson, Nat. Commun., 2018, 9, 4170.

21. J. Mahamid, A. Sharir, L. Addadi and W. S., P Natl. Acad. Sci. USA, 2008, 105, 12749-12753.

22. J. Mahamid, B. Aichmayer, E. Shimoni, R. Ziblat, C. Li, S. Siegel, O. Paris, P. Fratzl, S. Weiner and L. Addadi, P. Natl. Acad. Sci .USA 2010, 107, 6316-6321, S6316/6311-S6316/6316.

23. E. Beniash, R. A. Metzler, R. S. Lam and P. Gilbert, J. Struct. Biol. , 2009, 166, 133-143.

24. F. Ren, Y. Ding and Y. Leng, Biomed. Mater. Res. Part A, 2014, 102A, 496-505.

25. S. Diallo-Garcia, M. Ben Osman, J. M. Krafft, S. Casale, C. Thomas, J. Kubo and G. Costentin, J. Phys. Chem. C, 2014, 118, 12744-12757.

26. Z. H. Cheng, A. Yasukawa, K. Kandori and T. Ishikawa, J. Chem. Soc., Faraday Trans., 1998, 94, 1501-1505.

27. B. O. Fowler, M. Markovic and P. W. Brown, Chem. Mater., 1993, 5, 1417-1423.

28. M. Ben Osman, J. M. Krafft, Y. Millot, F. Averseng, T. Yoshioka, J. Kubo and G. Costentin, Eur. J. Inorg. Chem., 2016, 17, 2709-2720.

29. S. Koutsopoulos, J. Biomed. Mater. Res., 2002, 62, 600-612.

30. M. Pilarczyk, K. Czamara, M. Baranska, J. Natorszka, P. Kapusta, A. Undas and A. Kaczor, J. Raman Spectrosc., 2013, 44, 1222-1229.

31. G. B. Ramírez-Rodríguez, J. M. Delgado-López and J. Gómez-Morales, CrystEngComm, 2013, 15, 2206-2212.

32. A. Antonakos, E. Liarokapis and T. Leventouri, Biomaterials 2007, 28, 3043-3054.

33. M. D. Morris and G. S. Mandair, Clin. Orthop. Relat. Res., 2011, 469, 2160-2169.

34. G. L. Darimont, B. Gilbert and R. Cloots, Mater. Lett., 2003, 58, 71-73.

35. M. M. Kerssens, P. Matousek, K. Rogersb and N. Stone, Analyst, 2010, 135, 3156-3161.

36. Y. Leng, J. Chen and S. Qu, Biomaterials, 2003, 24, 2125-2131.

37. R. Xin, Y. Leng and N. Wang, J. Crystal Growth, 2006, 289, 339-344.

38. R. M. Wilson, J. C. Elliott, S. E. P. Dowker and L. M. Rodriguez-Lorenzo, Biomaterials, 2005, 26.

39. W. E. Brown, J. P. Smith, J. R. Lehr and A. W. Frazier, Nature, 1962, 196, 1050-1055.

40. M. Mathew, W. E. Brown, L. W. Schroeder and B. Dickens, J. Cryst. and Spectrosc., 1988, 18, 235-250.

41. S. Stewart, D. A. Shea, C. P. Tarnowski, M. D. Morris, D. Wang, R. Franceschi, D. L. Lin and E. Keller, J Raman Spectrosc., 2002, 33, 536-543.

42. A. Akiva, M. Kerschnitzki, I. Pinkas, W. Wagermaier, K. Yaniv, P. Fratzl, L. Addadi and S. Weiner, J. Am. Chem. Soc., 2016, 138, 14481-14487.

43. E. Davies, K. H. Muller, W. C. Wong, C. J. Pickard, D. G. Reid, J. N. Skepper and M. Duer, P Natl. Acad. Sci. USA, 2014, 111, E1354-E1363.

44. E. Davies, M. J. Duer, S. E. Ashbrook and J. M. Griffin, J. Am. Chem. Soc., 2012, 134, 1250812515.

45. G. Cho, Y. Wu and J. L. Ackerman, Science, 2003, 16, 1123-11127.

46. W. P. Rothwell, J. S. Waugh and J. P. Yesinowski, J. Am. Chem. Soc., 1980, 102, 2637-2643.

47. W. P. Aue, A. E. Roufosse, M. J. Glimcher and R. G. Griffin, Biochemistry, 1984, 23,25, 61106114. 
48. A. H. Roufosse, W. P. Aue, J. E. Roberts, M. J. Glimcher and R. G. Griffin, Biochemistry, 1984, 23, 6115-6120.

49. C. Jäger, T. Welzel, W. Meyer-Zaika and M. Epple, Magn. Reson. Chem., 2006, 44, 573-580.

50. N. Nassif, F. Martineau, O. Syzgantseva, F. Gobeaux, M. Willinger, T. Coradin, S. Cassaignon, T. Azaïs and M. M. Giraud-Guille, Chem. Mater. , 2010, 22, 3653-3663.

51. A. Bigi, B. Bracci, S. Panzavolta, M. lliescu, M. Plouet-Richard, J. Werckmann and D. Cam, Crystal Growth \& Design, 2004, 4, 141-146.

52. D. Massiot, F. Fayon, M. Capron, I. King, S. Le Calvé, B. Alonso, J.-O. Durand, B. Bujoli, Z. Gan and G. Hoatson, Magn. Reson. Chem., 2002, 40, 70-76.

53. J. Rodriguez-Carvajal, http://www-llb.cea.fr/fullweb/fp2k/fp2k divers.htm), 2005.

54. L. M. Rodríguez-Lorenzo, J. N. Hart and K. A. Gross, J Phys. Chem. B, 2003, 107, 8316-8320.

55. M. E. Fleet and X. Liu, J. Solid State Chem., 2004, 177, 3174-3182.

56. M. E. Fleet, X. Liu and X. Liu, Am. Miner., 2011, 96, 1148-1157.

57. A. Awonusi, M. D. Morris and M. M. Tecklenburg, Calcif. Tissue Int., 2007, 81, 46-52.

58. S. Von Euw, Y. Wang, G. Laurent, C. Drouet, F. Babonneau, N. Nassif and T. Azaïs, Sci. Rep., 2019, 9, 8456.

59. J. D. Pasteris, B. Wopenka, J. J. Freeman, K. Rogers, E. Valsami-Jones, J. A. van der Houwen and M. J. Silva, Biomaterials, 2004, 25, 229-238.

60. M. R. Urist, Fundamental and Clinical Bone Physiology, J.B. Lippincott Co., Philadelphia, 1980.

61. J. D. Currey, Bones: Structure and Mechanics, Princeton University Press, 2002.

62. N. Vandecandelaere, C. Rey and C. Drouet, J. Mater. Sci. Mater. Med. , 2012, 23, 2593-2606.

63. K. Chatzipanagis, M. lafisco, T. Roncal-Herrero, M. Bilton, A. Tampieri, R. Kröger and D.-L. J.M., CrystEngComm, 2016, 18, 3170-3173.

64. S. Von Euw, W. Ajili, A. Delices, G. Laurent, F. Babonneau, N. Nassif and T. Azaïs, Acta biomater., 2017, 59, 351-360.

65. M. J. Glimcher, L. C. Bonar, M. D. Grynpas, W. J. Landis and A. H. Roufosse, J. Cryst. Growth 1981, 53, 100-119.

66. L. Brečević and H. Füredi-Milhofer, Calc. Tiss. Res., 1972, 10, 82-90.

67. R. L. Frost, Y. Xi, R. E. Pogson, G. J. Millar, K. Tan and S. J. Palmer, J. Raman Spectrosc., 2012, 43, 571-576.

68. J. C. Elliot, Structure and Chemistry of the Apatites and Other Calcium Orthophosphates., Elsevier, Amsterdam, Neth., 1994.

69. V. F. Shamrai, A. E. Karpikhin, A. Y. Fedotov, V. P. Sirotinkin, S. M. Barinov and V. S. Komlev, Inorganic Materials, 2015, 51, 355-361.

70. T. W. T. Tsai, F.-C. Chou, Y.-H. Tseng and J. C. C. Chan, Phys. Chem. Chem. Phys. , 2010, 12, 6692-6697.

71. D. Shen, N. Horiuchi, S. Nozaki, M. Miyashin, K. Yamashita and A. Nagai, Biomed. Mater. Eng., 2017, 28, 9-21. 
Monitoring apatite formation through in situ RAMAN and ex situ ssNMR spectroscopies

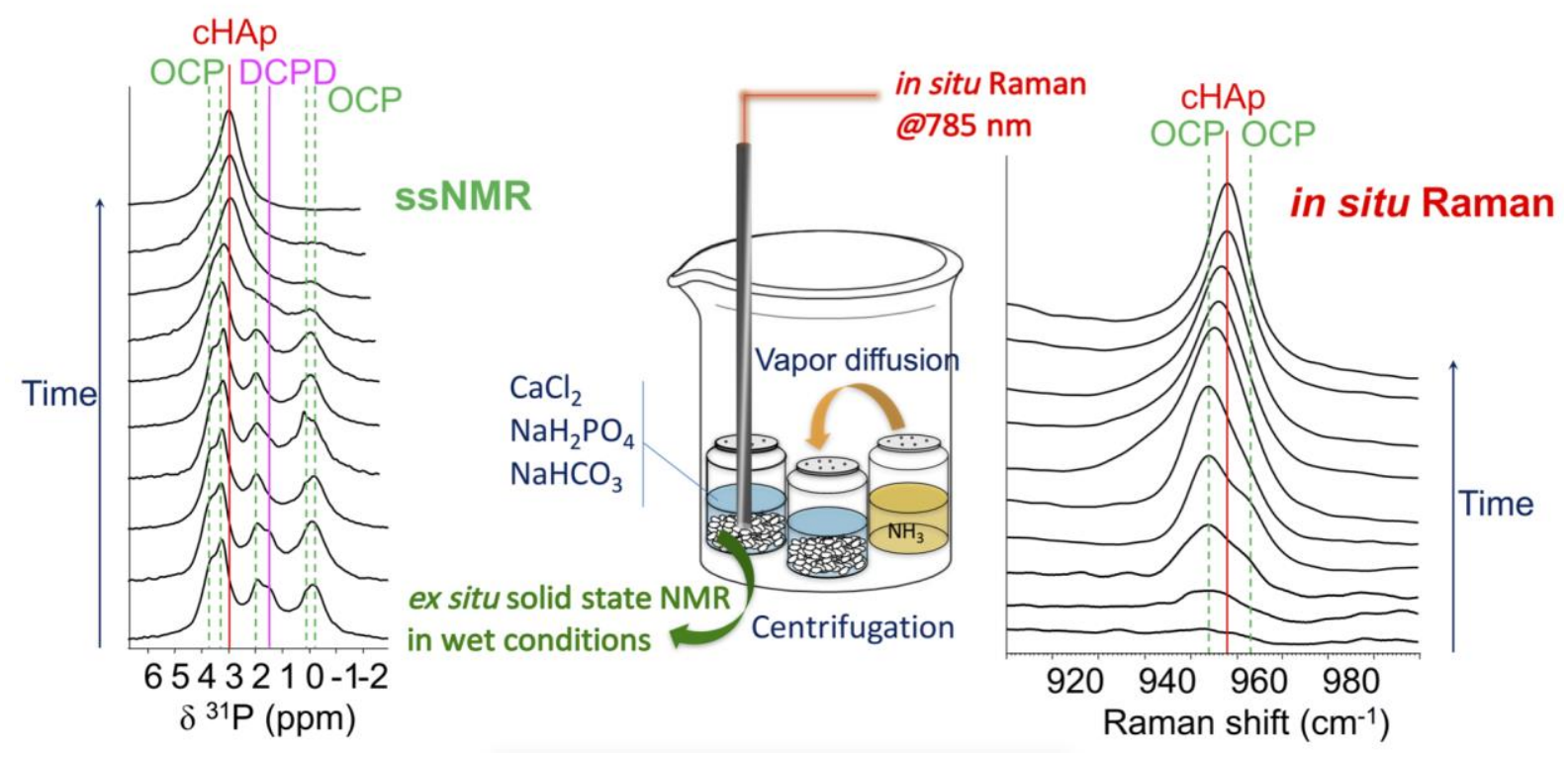




\section{Electronic Supplementary Information}

\section{Insights for OCP Identification and Quantification in the Context of Apatite Biomineralization}

Marc Robin ${ }^{\mathrm{a}, \mathrm{b}}$, Stanislas Von Euw ${ }^{\mathrm{a}}$, Guillaume Renaudin ${ }^{\mathrm{c}}$, Sandrine Gomes ${ }^{\mathrm{c}}$,

Jean-Marc Krafft ${ }^{b}$, Nadine Nassif ${ }^{a}$, Thierry Azaïs ${ }^{a^{*}}$ and Guylène Costentin ${ }^{b *}$

a Sorbonne Université, CNRS, Collège de France, Laboratoire Chimie de la Matière Condensée de Paris, LCMCP, F-75005 Paris, France

${ }^{b}$ Sorbonne Université, CNRS, Laboratoire Réactivité de Surface, LRS, F-75005 Paris, France

' Université Clermont Auvergne, CNRS, SIGMA Clermont, ICCF, F-63000 Clermont-Ferrand, France

Corresponding authors: thierry.azais@upmc.fr; guylene.costentin@upmc.fr 


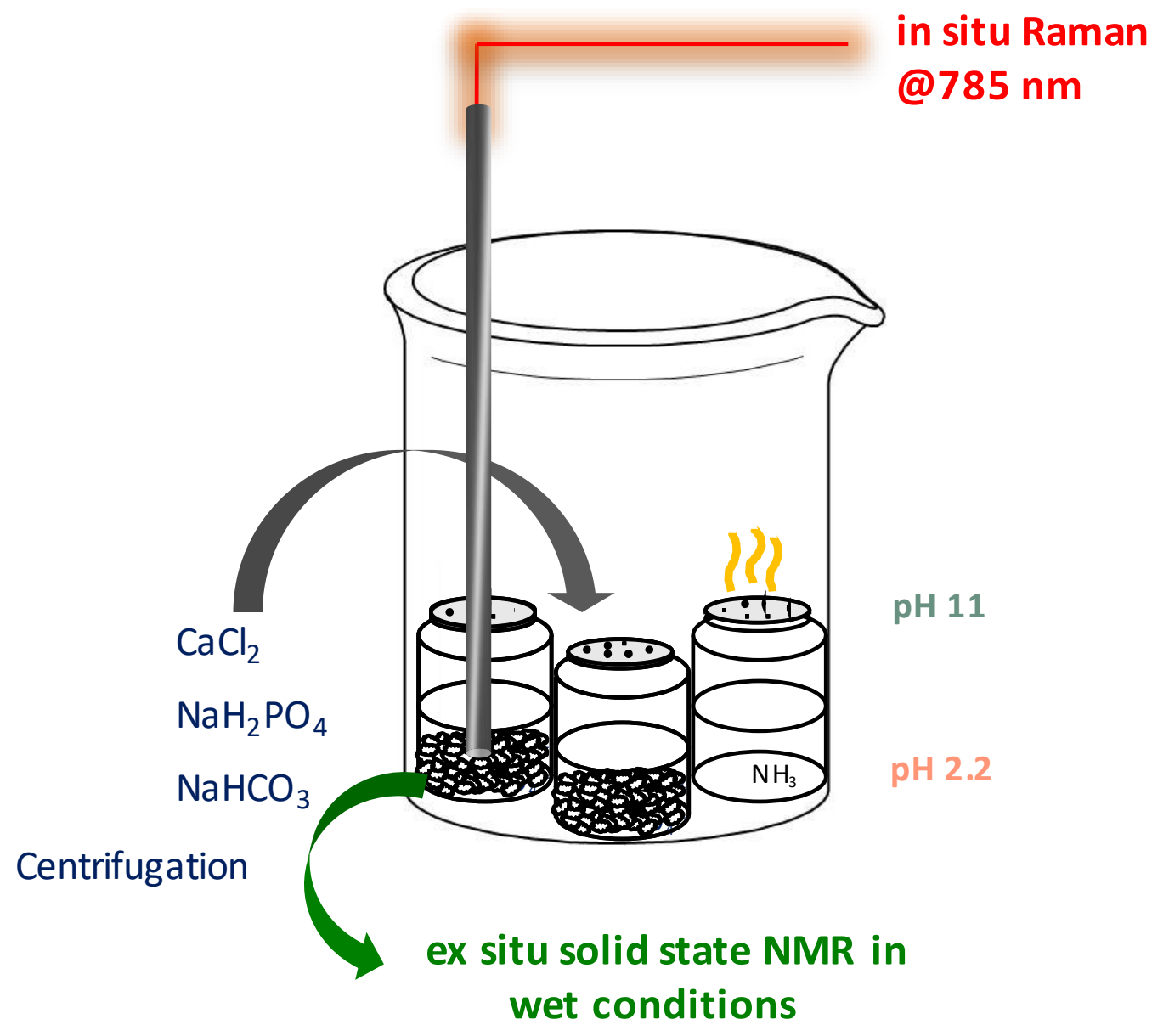

Figure S1. Schematic representation of the original set-up used to monitor the precipitation of biomimetic apatite (cHAp). 

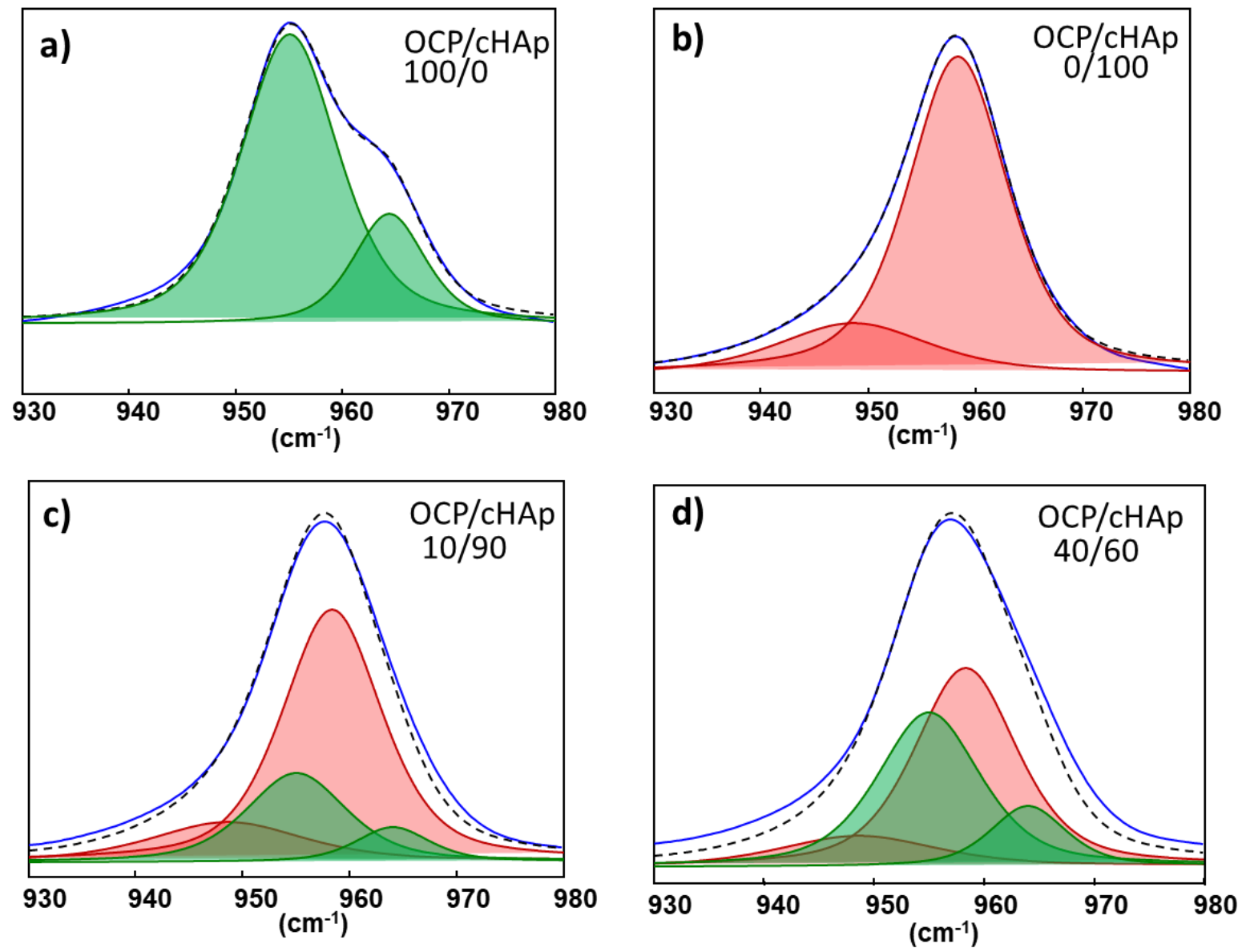

Figure S2. Spectral decomposition Raman spectra in the $v_{1} \mathrm{PO}_{4}$ region for a) pure $\left.O C P, \boldsymbol{b}\right)$ pure $c H A p$ and c) and d) $\mathrm{OCP} / \mathrm{cHAp}$ physical mixtures with weight ratio of 10/90) and 40/60, respectively. In these two latter cases, the two set of components extracted for pure OCP and CHAp samples (band positions, linewidths and the relative intensities of the two components present in the pure $O C P$ (955 and $964 \mathrm{~cm}^{-}$ $\left.{ }^{1}\right)$ and $\mathrm{cHAp}$ (958 and $950 \mathrm{~cm}^{-1}$ ) samples were kept constant. The estimated compositions deduced from the extracted contributions of the fits for the two physical mixtures (27/73 and $45 / 55$, respectively) are however not in good accordance with the nominal ones, which is explained by the numerous parameters (surface/volume ratio, diffusion) impacting the intensities of the Raman contributions. Experimental spectrum in blue, $v_{1} \mathrm{PO}_{4}$ bands related to OCP in green, $v_{1} \mathrm{PO}_{4}$ bands related to CHAp in red, sum in dashed black. 
S3 Decomposition of ${ }^{31} \mathrm{P}$ NMR spectra of physical mixtures of OCP and cHAp and calibration curve.
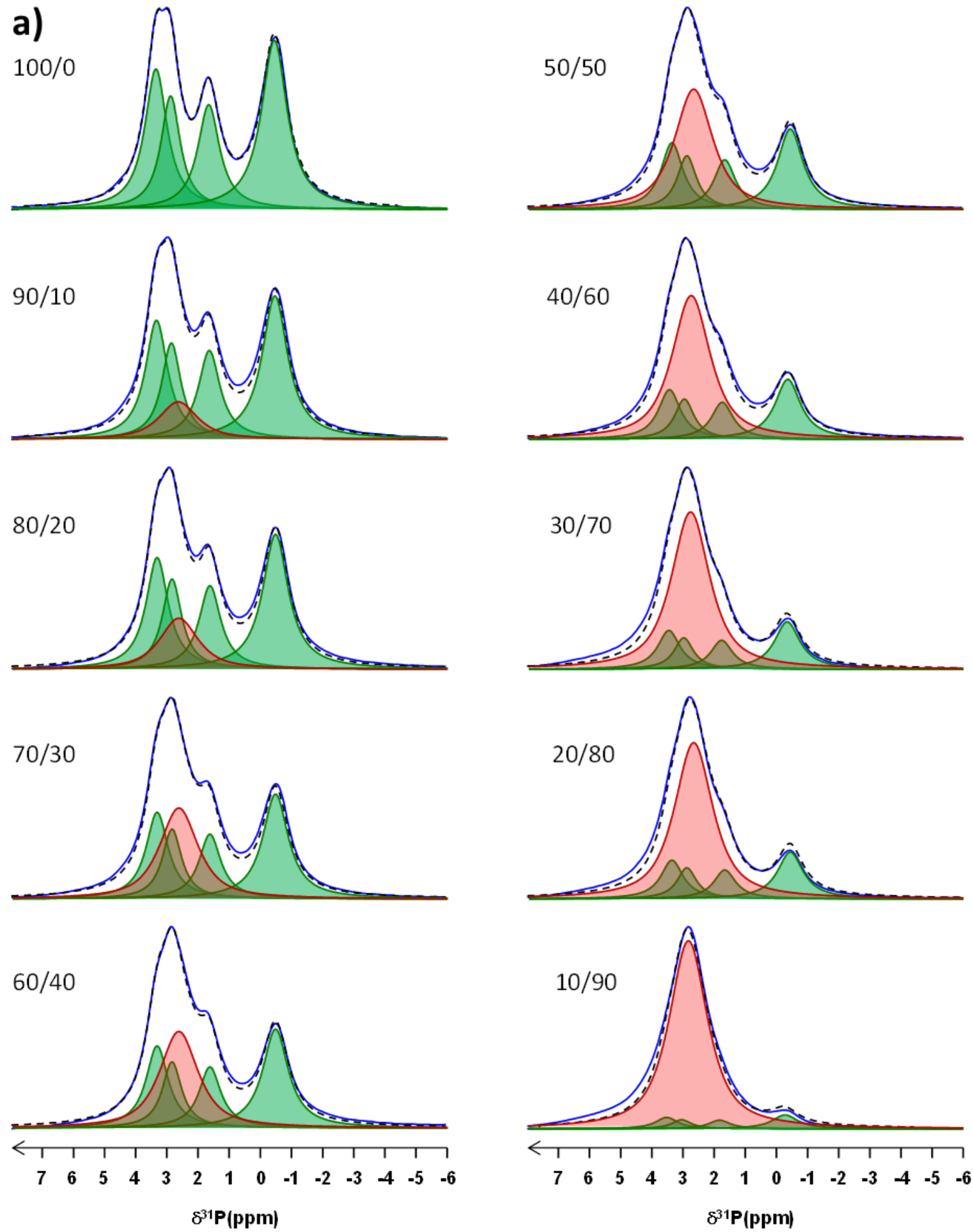

Figure $\mathbf{S 3 a}$ : decomposition of the ${ }^{31} P$ ssNMR spectra of the OCP/CHAp physical mixtures. Experimental spectrum in blue, resonances corresponding to OCP in green, to CHAp in red, sum in dashed black. The relative $\mathrm{OCP} / \mathrm{CHAp}$ nominal weight fraction are indicated onto each spectrum. 
b)

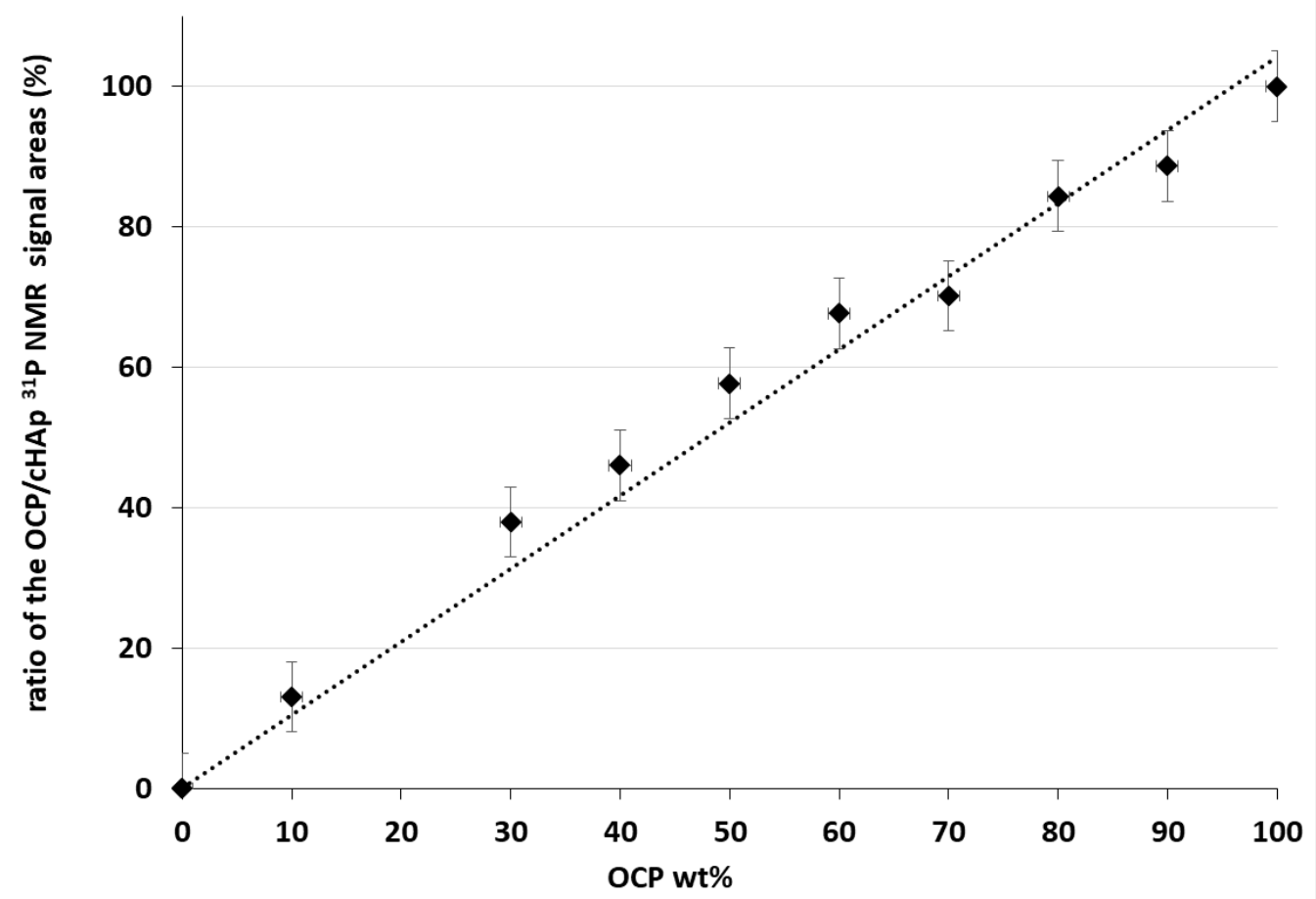

Figure $\mathbf{S} 3 \boldsymbol{b}$ : relationship between the wt\% OCP in the OCP/CHAp physical mixture and the \% of the area of OCP phosphate components as determined through ${ }^{31} P$ sSNMR to be used as calibration curve for relative quantification. The relative precision that can be estimated about $\pm 5 \%$ in our conditions. 


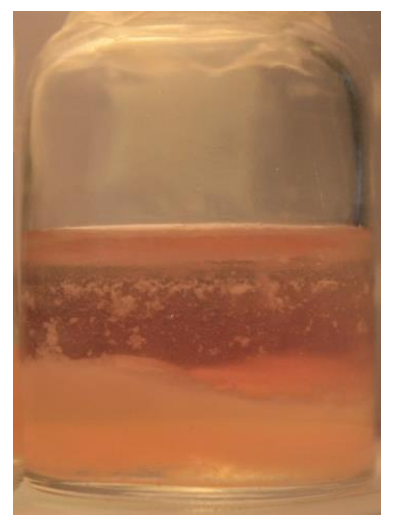

Video S4. Video (web enhanced object) of the precipitation of biomimetic apatite in one of the two flasks. The $\mathrm{pH}$ is indicated by the changes in the $\mathrm{pH}$ indicator colour. Web-Enhanced object is available.

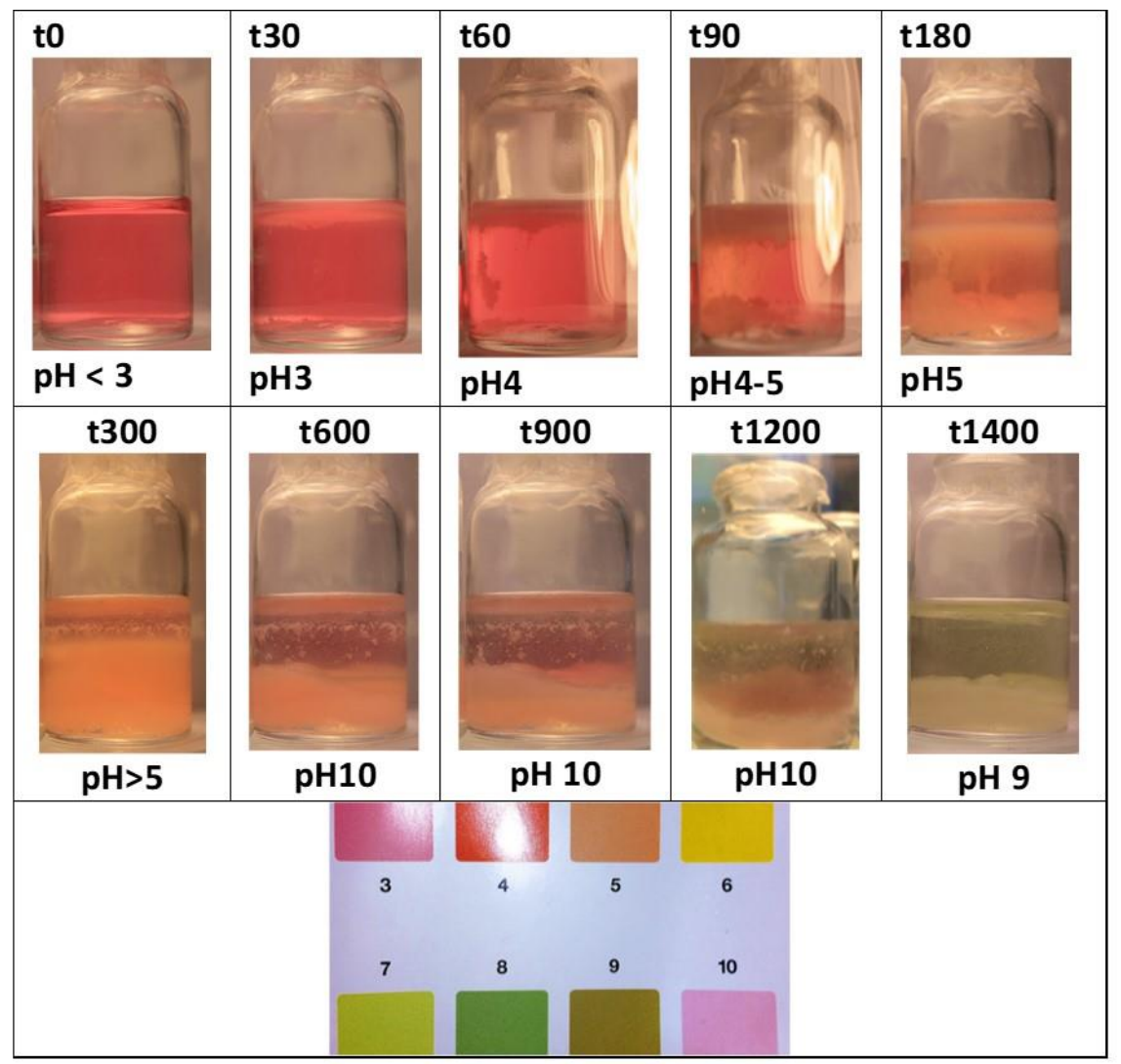

Figure S4. Selection of pictures indicating the evolution of the $\mathrm{pH}$ values upon increasing reaction time and corresponding $\mathrm{pH}$ value at the bottom of the reactor deduced from universal indicator solution $\mathrm{pH}$ (Fluka-31282). 
S5 Spectral decomposition of ${ }^{31} \mathrm{P}$ NMR spectra recorded during precipitation of biomimetic apatite
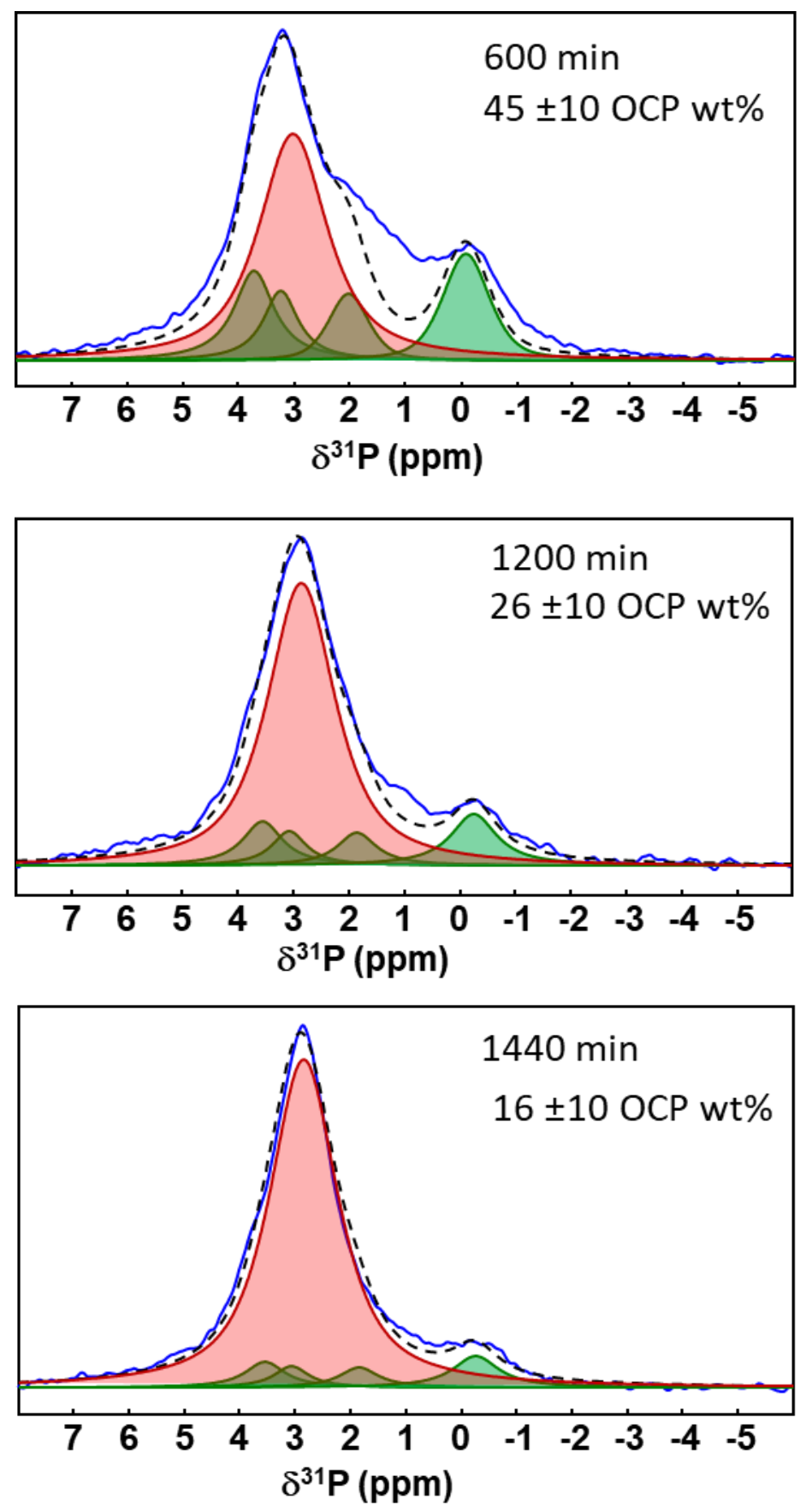

Figure S5: decomposition of the ${ }^{31} P$ sSNMR spectra of the reaction products during the formation of biomimetic CHAp. Experimental spectrum in blue, resonances corresponding to OCP in green, to CHAp in red, sum in dashed black. The OCP weight fraction that is deduced from the decomposition and the calibration curve (Fig. $\mathrm{S3b}$ ) is indicated onto each spectrum together with the reaction time. 
S6 Rietveld refinement of our OCP sample showing concluding to adequacy with OCP structure model.

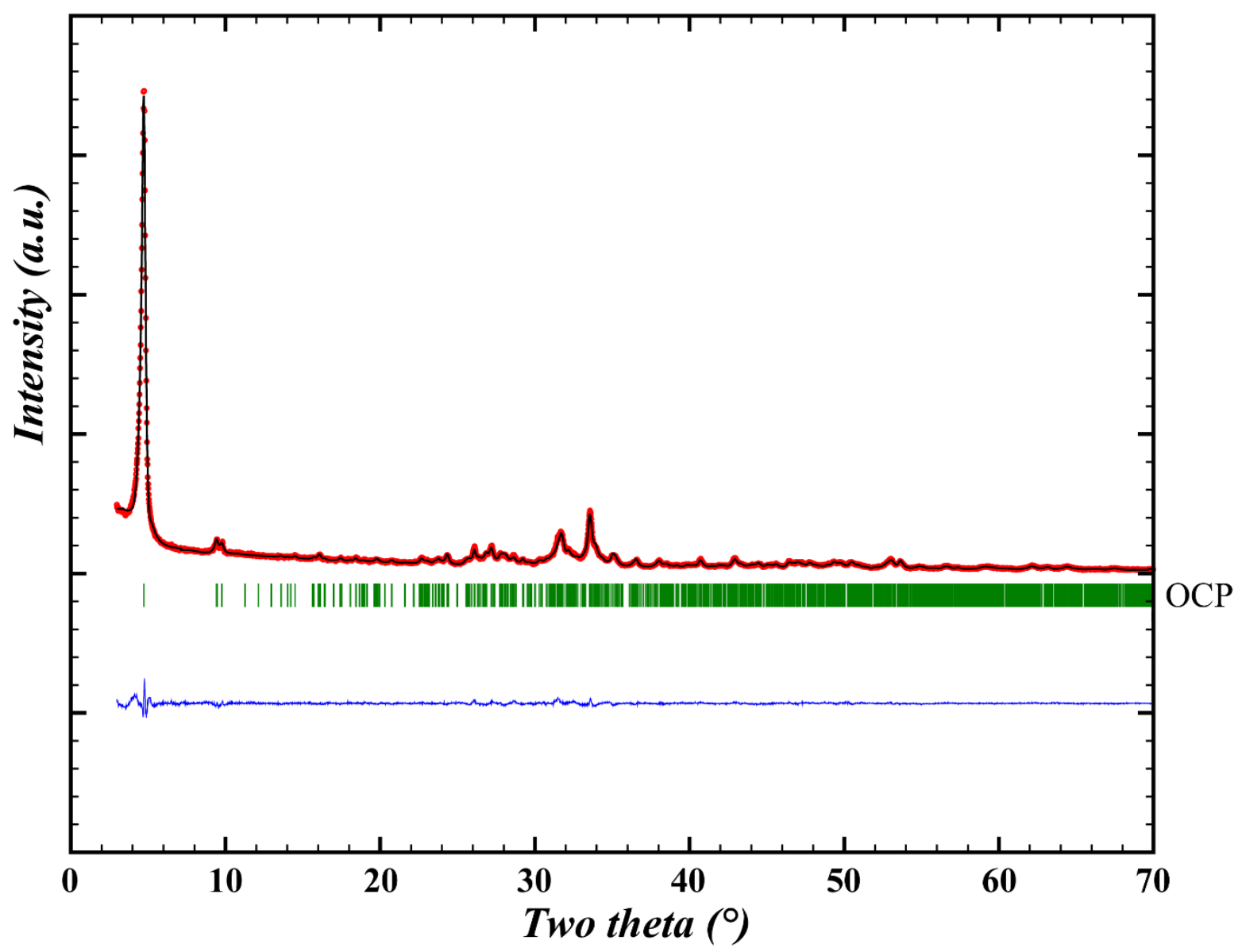

Figure S6. Rietveld plot of our OCP sample showing the adequacy between the OCP model structure and our synthetic single-phase OCP sample $\left(R_{p}=0.05, R_{w p}=0.04\right.$ and $\chi^{2}=2.14$. $)$ : red point for experimental measurement, black line for calculated pattern, blue line for difference curve and green sticks for OCP Bragg positions ( $\lambda=1.5418 \AA$ ). 
Table S6: Structure parameters for OCP compound extracted from Rietveld refinement (standard deviation indicated in bracket) and comparison with values from literature.

\begin{tabular}{|c|c|c|c|}
\hline & & Synthetic OCP & Mathew et al. ${ }^{1}$ \\
\hline OCP & a $(\AA ̊)$ & $19.7084(6)$ & $19.692(4)$ \\
\hline \multirow[t]{6}{*}{ parameters } & $b(\AA)$ & 9.5405 (5) & $9.523(2)$ \\
\hline & $c(\AA)$ & $6.8367(3)$ & $6.835(2)$ \\
\hline & $\alpha\left({ }^{\circ}\right)$ & $90.143(4)$ & $90.15(2)$ \\
\hline & $\beta\left({ }^{\circ}\right)$ & $92.517(3)$ & $92.54(2)$ \\
\hline & $\gamma\left({ }^{\circ}\right)$ & $108.317(2)$ & $108.65(1)$ \\
\hline & $V\left(\AA^{3}\right)$ & $1219.00(9)$ & 1213.1 \\
\hline \multirow[t]{3}{*}{ Rietveld agreement } & $\chi^{2}$ & 2.14 & \\
\hline & $\mathrm{Rp}(\%)$ & 4.05 & \\
\hline & Rwp (\%) & 5.22 & \\
\hline
\end{tabular}



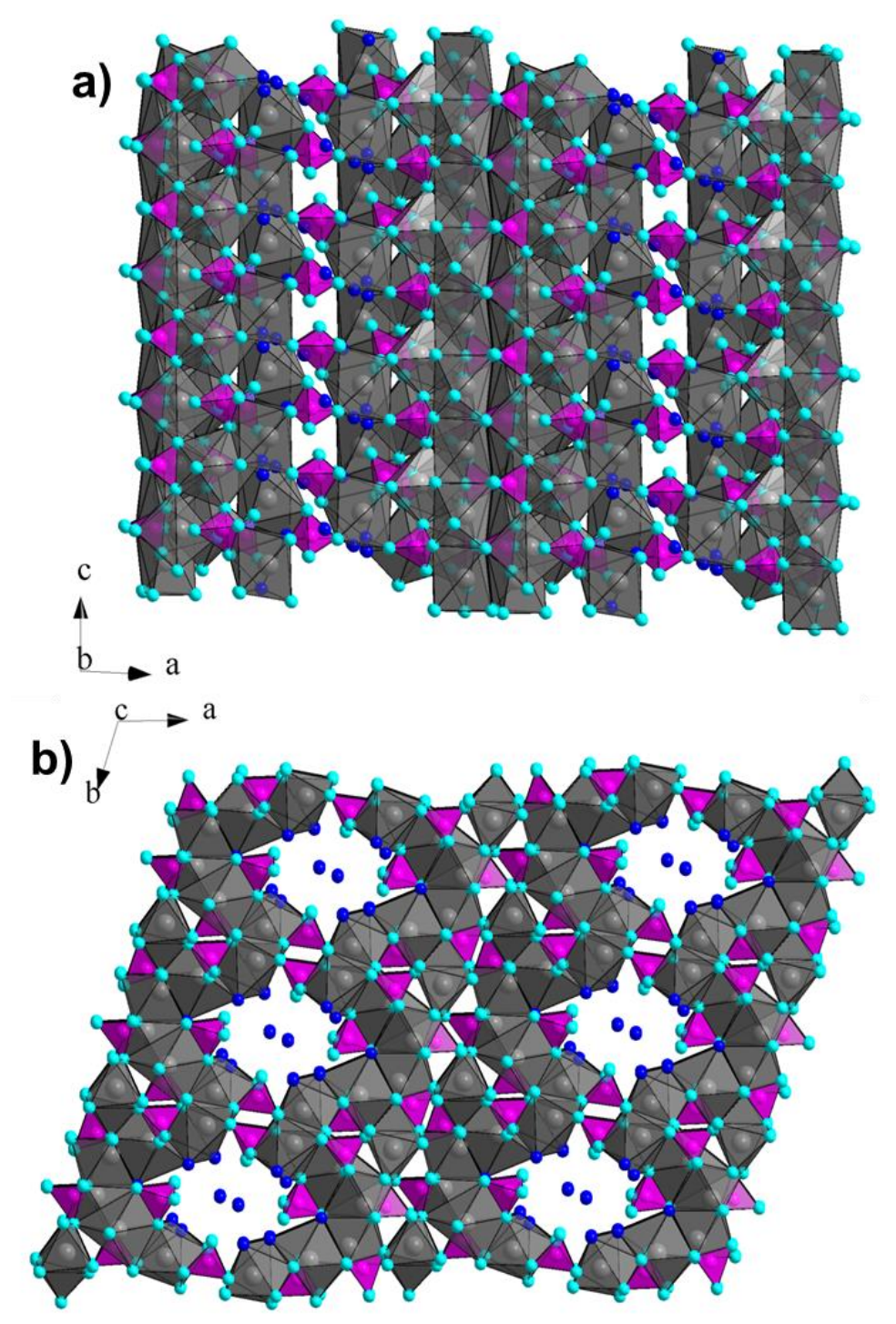

Figure S7: projection of the OCP structure along $a)$ the $b$ axis and $b)$ the $c$ axis. Purple tetrahedra correspond to $\mathrm{PO}_{4}{ }^{3-}$ and $\mathrm{HPO}_{4}{ }_{4}^{2-}$, grey polyhedron to coordination spheres of $\mathrm{Ca}^{2+}$, cyan spheres to $\mathrm{O}^{2-}$ or $\mathrm{OH}^{-}$of phosphate groups and blue spheres to water molecules. 
S8: Rietveld simulations accounting for the modification of the relative intensity of the (100) diffraction line of OCP.

As shown in Fig. S8, the removal of the water molecule located inside the large column of the OCP unit cell (leading to a theoretical composition of “ $\mathrm{Ca} 8\left(\mathrm{HPO}_{4}\right)_{2}\left(\mathrm{PO}_{4}\right)_{4} \cdot 4 \mathrm{H}_{2} \mathrm{O}$ ”), or the removal of all the water molecules from the hydrated layer (theoretical composition of " $\mathrm{Ca}_{8}\left(\mathrm{HPO}_{4}\right)_{2}\left(\mathrm{PO}_{4}\right)_{4} \cdot \mathrm{OH}_{2} \mathrm{O}$ "), lead to the increase of the (100) reflection relative intensity compared to the $(1 \overline{1} 0)$ and $(010)$ reflections whereas reflexions at high angles (from $20^{\circ}$ ) are not significantly modified (not shown). On the other hand, increasing of the electronic density within an equivalent of 1 water molecules added inside the large column (theoretical composition of " $\mathrm{Ca}_{8}\left(\mathrm{HPO}_{4}\right)_{2}\left(\mathrm{PO}_{4}\right)_{4} \cdot 6 \mathrm{H}_{2} \mathrm{O}$ "), or formally doubling the electronic density on each water position (theoretical composition of " $\mathrm{Ca}\left(\mathrm{HPO}_{4}\right)_{2}\left(\mathrm{PO}_{4}\right)_{4} \cdot 10 \mathrm{H}_{2} \mathrm{O}$ "), resulted in the significant decrease of the intensity of the (100) reflexion as observed experimentally for cHAp-1d, cHAp-2d and cHAp-3d samples (Fig. S8).

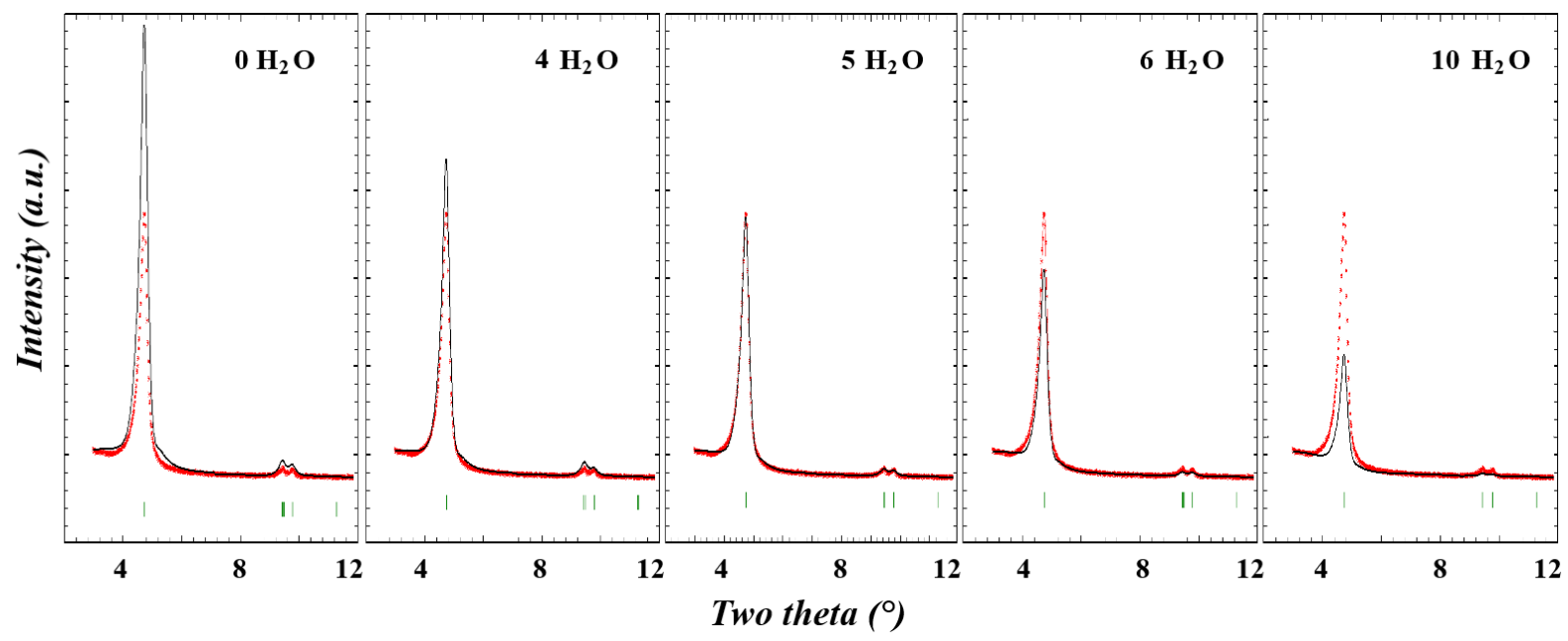

Figure S8: Rietveld simulations displaying the impact of the electronic density expressed as $n$ equivalent of water molecules within the hydrated layer of the OCP structure (i.e. $\mathrm{Ca}_{8}\left(\mathrm{HPO}_{4}\right)_{2}\left(\mathrm{PO}_{4}\right)_{4} \cdot n \mathrm{H}_{2} \mathrm{O}$ with $n=$ $0,4,5,6$ and 10) on the scattered intensity of the first (100) Bragg peak. Red dotted lines and black lines represent the experimental pattern of pure OCP sample and the simulated one with $n$ water molecules respectively. 